\title{
A regional coupled approach to water cycle prediction during winter 2013/14 in the United Kingdom
}

\author{
Huw W. Lewis ${ }^{1}$ @ | Simon J. Dadson ${ }^{2}$
}

${ }^{1}$ Met Office, Exeter, UK

${ }^{2}$ UK Centre for Ecology \& Hydrology, Wallingford, UK

\section{Correspondence}

Huw W. Lewis, Met Office, Exeter EX1 3PB,

UK.

Email: huw.lewis@metoffice.gov.uk

Funding information

Natural Environment Research Council, Grant/ Award Number: NE/S017380/1

\section{1 | INTRODUCTION}

Winter 2013/14 in the United Kingdom (UK) was notable for the cumulative impacts of a series of successive damaging storms crossing

\begin{abstract}
A regional coupled approach to water cycle prediction is demonstrated for the 4-month period from November 2013 to February 2014. This provides the first multicomponent analysis of precipitation, soil moisture, river flow and coastal ocean simulations produced by an atmosphere-land-ocean coupled system focussed on the United Kingdom (UK), running with horizontal grid spacing of around $1.5 \mathrm{~km}$ across all components. The Unified Model atmosphere component, in which convection is explicitly simulated, reproduces the observed UK rainfall accumulation $\left(r^{2}\right.$ of 0.95 for water day accumulation), but there is a notable bias in its spatial distribution-too dry over western upland areas and too wet further east. The JULES land surface model soil moisture state is shown to be in broad agreement with a limited number of cosmic-ray neutron probe observations. A comparison of observed and simulated river flow shows the coupled system is useful for predicting broad scale features, such as distinguishing high and low flow regions and times during the period of interest but are less accurate than optimized hydrological models. The impact of simulated river discharge on NEMO model simulations of coastal ocean state is explored in the coupled modelling framework, with comparisons provided relative to experiments using climatological river input and no river input around the UK coasts. Results show that the freshwater flux around the UK contributes of order 0.2 psu to the mean surface salinity, and comparisons to profile observations give evidence of an improved vertical structure when applying simulated flows. This study represents the first assessment of the coupled system performance from a hydrological perspective, with priorities for future model developments and challenges for evaluation of such systems discussed.
\end{abstract}

\section{KEYWORDS}

coastal regions of freshwater influence, coupled modelling, water cycle prediction

This is an open access article under the terms of the Creative Commons Attribution License, which permits use, distribution and reproduction in any medium, provided the original work is properly cited.

(C) 2021 Crown Copyright. Hydrological Processes published by John Wiley \& Sons Ltd. This article is published with the permission of Controller of HMSO and the Queen's Printer for Scotland. 
sources (Muchan et al., 2015). Such events provide strong motivation for adopting a more holistic approach to understanding and quantifying the risks to populations and infrastructure from compound flooding from multiple sources and from concurrent hazards (Ciurean et al., 2018; Pilling et al., 2016).

The coupling or linking of different environmental models has long been considered a necessary approach to achieving this more holistic view. This vision was well expressed by Beven (2007; quote below reproduced with kind permission of the author), who invited readers to:

\begin{abstract}
"Consider, for flood prediction purposes, the possibility of modelling the subtle (and interdisciplinary) coupling between atmospheric forcing, catchment response, river runoff and coastal interaction with tidally dominated sea levels; capturing these subtleties will require the dynamical coupling of many processes and components from different institutes and different computing systems. Components would be a representation of the coastal seas, the regional atmosphere and the terrestrial surface and subsurface hydrology that would interact through different boundary conditions." (reproduced from Beven, 2007).
\end{abstract}

For typical hydrological and risk assessment applications, any coupling of models and data has been achieved by defining linear model chains whereby outputs from one system (e.g., point or distributed observation, numerical weather prediction or climate simulation based data) are fed into a hydrological and/or hydraulic model in order to simulate the land surface response and risk of flood hazard (e.g., Coxon et al., 2019a; Flack et al., 2019; Ming et al., 2020). For coastal flood hazards, for example, Couasnon et al. (2020) recently illustrated the need to consider both fluvial and coastal flood drivers in the estimation of compound flood risk at coastal locations at a global scale, with river and coastal surge data obtained from two independent sources, although with both driven by the same ERA-Interim reanalysis of the meteorological forcing.

The vision for the dynamical coupling between atmosphere, catchment, rivers and coastal components as set out by Beven (2007) is more closely achieved by adopting a fully coupled approach whereby model components exchange information at run-time via a coupler so that interactions and feedbacks are explicitly simulated. This is well established and illustrated through the evolution of Earth System Models to assess the drivers, sensitivities and impacts of environmental change on global scales (e.g., Sellar et al., 2019). The key challenges for improving how hydrological processes are represented in these systems were discussed by Clark et al. (2015), while Ward et al. (2020) recently addressed the importance of and priorities for better representing the land-ocean interface in Earth System Models.

On regional scales, the development of analogous dynamically coupled Regional Environmental Prediction systems is helping to underpin more whole-system simulations at more catchment and coastal-relevant scales. This is driven by needs to improve short-term hazard prediction (e.g., Senatore et al., 2015; Rainaud et al., 2017;
Zhang et al., 2021) and provision of more integrated longer-timescale assessments of environmental change (e.g., Giorgi, 2019). To date, regional coupled systems have tended to be developed with a view to improving either the integration of meteorological and hydrological predictions (e.g., Fersch et al., 2019), or with a focus on better representing the impacts of air-sea interactions on the system through coupling atmosphere and ocean (and occasionally wave) model components (e.g., Strajnar et al., 2019; Thompson et al., 2019; Varlas et al., 2018; Warner et al., 2010). Senatore et al. (2020) bridged these perspectives to some extent in assessing the impact of different sea surface temperature (SST) forecasts used as the lower boundary condition on the hydrological performance of a $\mathrm{km}$-scale regional atmosphere-land simulations focussed on southern Italy. While based on results from only two relatively short case studies, they highlighted differences in precipitation and streamflow simulations when different SST were used. It should also be noted however that a stronger sensitivity was found to the choice of driving model providing lateral atmospheric boundary conditions and many other uncertainties in the water cycle modelling chain were not explored.

Durnford et al. (2017) arguably provide the closest realization to a fully coupled water cycle prediction system on regional scales. The development led by Environment Canada couples interacting regional atmosphere, land surface, river routing and 3-d lake models and provides operational hydrological forecasts on short-to-medium range timescales for the Great Lakes-St. Lawrence Seaway region of North America. This builds on a detailed analysis of the sensitivity of net basin supply to meteorological forcing and land surface model parameterization conducted by Deacu et al. (2012). Based on an 8-day summer period and longer 4-month evaluation simulations, Durnford et al. (2017) assessed the hydrological performance of the system in terms of simulated precipitation, river flows, lake inflows and water levels, along with more oceanic variables of lake surface currents and temperature. Lake ice forecasts were also illustrated for a winter period. The system was shown to produce reliable results for a 3.5-day forecast, with atmosphere and lake water results considered to be more mature and reliable than those from the river routing model. Critically, it was found that assimilation of observed river flow was required to limit the propagation of precipitation errors into the predicted river flows and downstream to lake quantities.

To the authors' knowledge, this paper presents the first evidence of such a whole-system regional water cycle prediction approach focussed on the UK and surrounding shelf seas. Tonani et al. (2019) identified that addressing salinity errors at both basin and local scales within the operational $\mathrm{km}$-scale regional ocean model for the northwest European shelf seas as the most pressing improvement need. They described a practical choice to use climatological river discharge forcing into this system as it leads to improved salinity errors than when a pan-European river flow forecast product was used. Note that this same climatological river discharge forcing has been applied in previous studies using the regional coupled system discussed in this paper (e.g., Lewis et al., 2018; Lewis, Castillo Sanchez, et al., 2019).

The JULES (Joint UK Land Environment Simulator) land surface model is used to represent hydrological processes in the UK-focussed coupled system. In common with the evolution of other land surface 
models (Blyth et al., 2021; Clark et al., 2015), JULES is increasingly being applied and assessed with a view to have a more complete representation of terrestrial hydrology in addition to continuing focus on the representation of land-atmosphere coupling as has been more traditional in their use as an interacting lower boundary for weather and climate prediction. It has been previously demonstrated that JULES can provide accurate daily river flow simulations over selected catchments in Great Britain when driven by observation-based meteorological forcing (Martinez-de la Torre et al., 2019), while Gómez et al. (2020) demonstrated good river flow predictions when driven by an operational JULES-based regional land surface analysis. There are however known deficiencies in the hydrological performance of JULES over the UK, including excessive evaporation rates (Blyth et al., 2019), insufficient infiltration (Largeron et al., 2018) and numerous inherent parameterisation and parameter uncertainties (Martinezde la Torre et al., 2019). As discussed by Wagener et al. (2021), these uncertainties and limitations can in part be related to fundamental gaps in knowledge in how to represent the hydrology of the UK, which has led to a diversity of approaches, simplifications and use of data across different model structures. There are also known but important missing processes, notably representation of groundwater flows and storage, within JULES (Batelis et al., 2020) and other UKfocussed hydrological models (e.g., Coxon et al., 2019a). While treating precipitation and other meteorological-related inputs as an additional source of uncertainty among many (e.g., Wagener et al., 2021) can provide a practical constraint for model development, for example by optimizing model configurations with observed inputs, there have been critically few studies of the joint hydrometeorological performance of linked precipitation-to-river flow predictions for the UK (Anderson et al., 2019; Flack et al., 2019). This means that the impact of changes to the quality and characteristics of precipitation forecasts on resulting simulations of soil moisture and river flows are not routinely assessed, while the impact of atmosphere predictions on ocean forecasts tend to be focussed on direct radiation and surface weather forcing rather than an end-to-end assessment of hydrological forcing (e.g., Lewis, Siddorn, et al., 2019).

The utility and limitations of more coupled predictions to representing the UK's regional water cycle are therefore explored in this paper. Results from km-scale fully coupled regional atmosphere-landocean model simulations during UK winter 2013/14 are assessed, focussing on its hydrological performance. It is not considered feasible to use the coupled system as the primary means to isolate and address key model biases and uncertainties, relative to more component-specific and idealized simulations studies for example. Rather, the extent to which those biases are found to limit the quality of simulations of other model components within the system is assessed. The following specific questions are considered:

a. Are km-scale regional simulations of precipitation and soil moisture sufficiently accurate to provide useful forcing for distributed modelling of river flows across UK catchments?

b. How sensitive are regional ocean simulations of the near-coastal region around the UK to the representation and accuracy of input river flows? c. What do these results imply for future component model development?

The model system and its components are introduced in Section 2. Results are presented in Section 3, with a focus both on broad-scale model performance metrics and the near-coastal impacts of coupling the atmosphere-land system to the regional ocean. The implications of this work are discussed in Section 4 and conclusions briefly drawn in Section 5.

\section{DATA AND METHODS}

This study assesses the performance of a $\mathrm{km}$-scale regional atmosphere-land-ocean coupled prediction system focussed on the UK for simulations during the 4-month period covering winter 2013/14 between 30 October 2013 and 28 February 2014. Simulations use the UK coupled system and model grids detailed by Lewis et al. (2018) and Lewis, Castillo Sanchez, et al. (2019). Hourly mean variables are exchanged between model components using the OASIS3-MCT coupling libraries (Valcke et al., 2017) each hour through the simulation. All simulations are free running with no data assimilation applied to any component. Relevant aspects of each model component are briefly summarized below.

\subsection{Atmosphere model component}

The atmosphere component of the coupled system uses the Unified Model (UM; version 11.1) code, implicitly coupled to the JULES (Best et al., 2011; version 5.2) land surface model. Both components use the RAL1-M (Regional Atmosphere Land 1, mid-latitudes) science configuration documented by Bush et al. (2020). The variable resolution model grid is defined in rotated polar coordinates, with regular $1.5 \mathrm{~km}$ horizontal grid spacing in a central region focussed on the UK and stretching to $4 \mathrm{~km}$ spacing towards the outer domain edge (Figure 1). At this resolution, atmospheric convection is represented explicitly by the model dynamics rather than being parameterized. Lateral boundary conditions are applied hourly. These are provided by the first $24 \mathrm{~h}$ of operational global-scale Met Office numerical weather prediction (NWP) simulations archived from the time of the experiment, available then at a resolution of order $25 \mathrm{~km}$. Simulations are initialised by interpolating the operational global analysis valid for $\mathrm{OOZ}$ on 30 October 2013 to the regional grid.

\subsection{Land surface and river flow model component}

The RAL1 configuration of JULES has four soil layers to a depth of $3 \mathrm{~m}$ and surface land use heterogeneity is accounted for by defining the fractions of nine possible tiles of vegetation (broadleaf trees, needle-leaved trees, temperate C 3 grass, tropical C4 grass and shrubs) and non-vegetated land-use (urban areas, inland water, bare soil and 
(a)

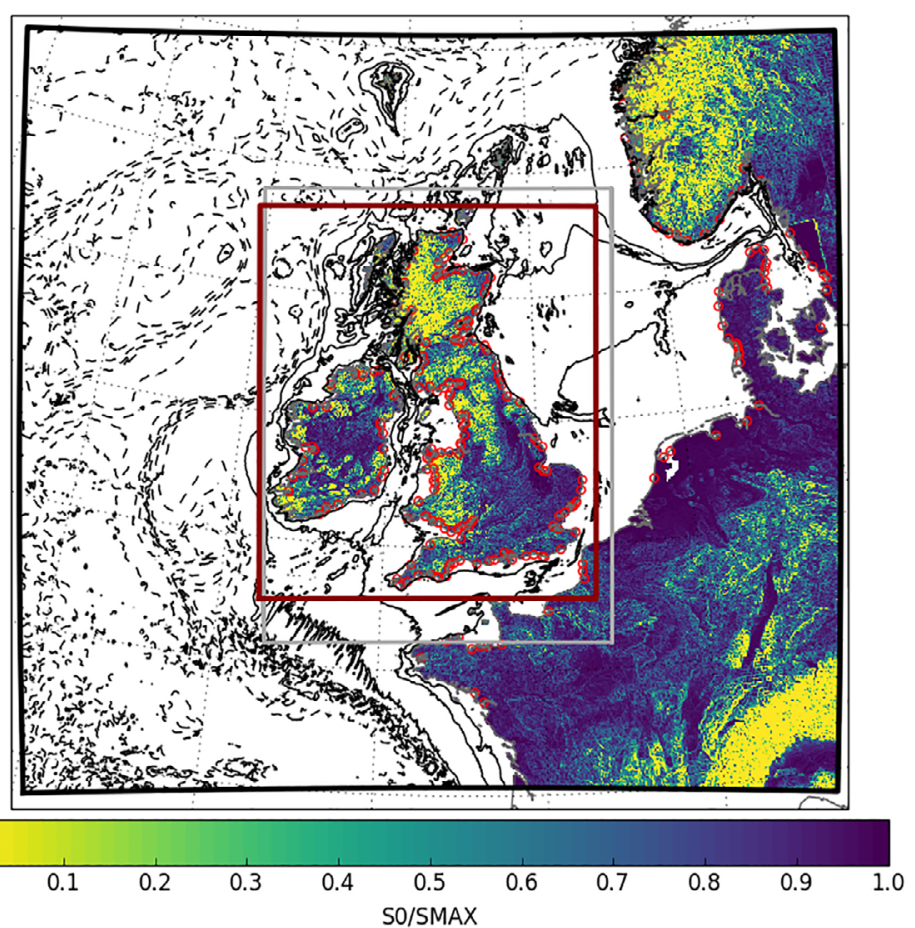

(b)

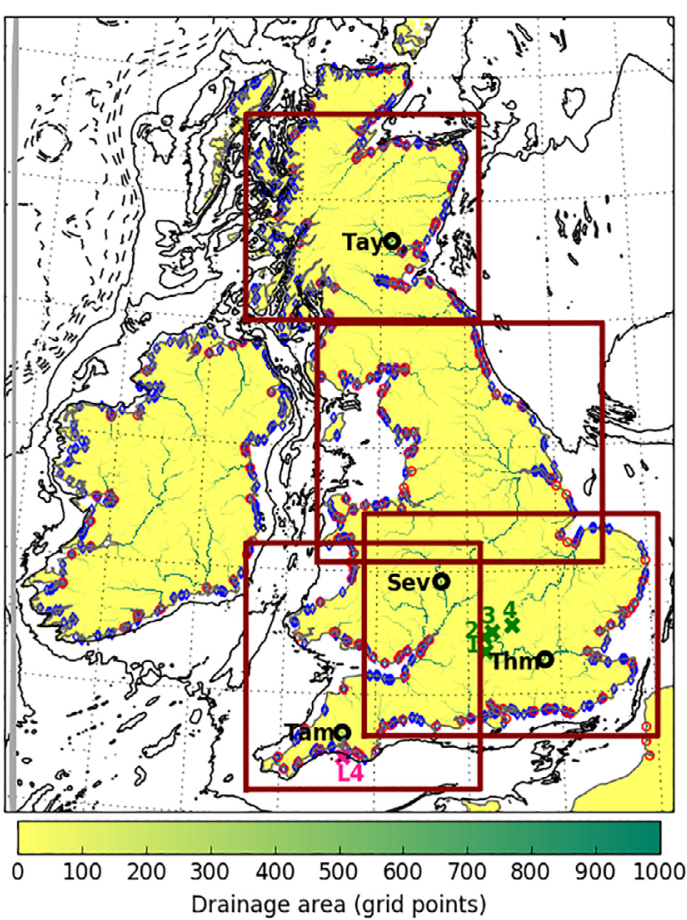

FIG URE 1 (a) Map of coupled model domain extent (black surrounding box). Shaded colours illustrate the $S_{0} / S_{\max }$ slope-dependent PDM parameter for each land grid point. Line contours show the ocean model bathymetry, with solid contours drawn every $50 \mathrm{~m}$ in locations where the ocean depth is shallower than $250 \mathrm{~m}$ and dashed contours every $500 \mathrm{~m}$ where the ocean is deeper. Red circles indicate the location of climatological river outflow points in the ocean model. The grey box indicates the region of regular $1.5 \mathrm{~km}$ horizontal grid spacing in atmosphere and land surface model components. (b) Zoom of the UK and Ireland region of the model domain (red box in (a)) with shading illustrating the upstream number of grid cells of the river routing grid. The locations of gauge observations on the rivers Tay, Severn [Sev], Thames [Thm] and Tamar [tam] are shown by black open circles. The location of the L4 ocean buoy off the south-West England coast is shown as a pink cross. The location of Sheepdrove [1], chimney meadows [2], Wytham Woods [3] and Waddesdon [4] COSMOS-UK soil moisture cosmic probe observation sites are indicated by green crosses. Red circles show the location of climatological outflow points in the ocean model (as in (a)). Blue diamonds indicate the location of ocean model river outflow points in the coupled system. Other sub-regions considered in the study are highlighted for reference

land ice) types for each grid cell (Lewis et al., 2018). The Brooks and Corey formulation for soil hydraulic conductivity (Cosby et al., 1984) is used, based on the mapped soil sand, silt and clay fractions used in the operational regional NWP configuration (Bush et al., 2020). Subgrid-scale heterogeneity of soil moisture is computed using the Probability Distributed Model (PDM; Moore, 2007). The configuration used in this study adopts the PDM optimisations recommended by Martinez-de la Torre et al. (2019), developed from assessments of JULES simulations focussed on 13 UK catchments at $1 \mathrm{~km}$ resolution driven by 30 -years of an observation-based meteorological forcing. The main difference relative to the use of PDM in the RAL1 land surface model configuration used for operational NWP (Bush et al., 2020) is the introduction of a terrain slope-dependent formulation that enhances the surface runoff generated over steeper regions while requiring wetter soil conditions before surface runoff is produced over flatter regions, relative to the behaviour of the default PDM scheme. Dependence on terrain slope is introduced by making the ratio of the minimum volume of water stored in a gridbox below which there can be no surface saturation $\left(\mathrm{S}_{0}\right)$ relative to the maximum possible gridbox storage $\left(S_{\max }\right)$ vary as a function of local slope.) as a function of local slope (Martinez-de la Torre et al., 2019). This ratio is illustrated in Figure 1a) for the $1.5 \mathrm{~km}$ variable resolution grid used in this study. This parameterization constrains the surface runoff production to wetter periods over flatter regions and enhances it over steeper regions relative to the standard and non-spatially varying PDM parameters used in RAL1. Saturation excess generates surface runoff (Clark \& Gedney, 2008) while free drainage from the base of the soil column is treated as sub-surface runoff.

Accumulated surface and sub-surface runoff can be routed in JULES using the River Flow Model (RFM) implementation of the kinematic wave equation solution (Bell et al., 2007; Dadson et al., 2011). Water storages in each grid cell are computed and outflows routed to the downstream grid cell defined by a pre-calculated flow direction map linking adjacent points in the domain. The routing pathways are defined on the same $1.5 \mathrm{~km}$ resolution grid as used for the rest of the land surface (and atmosphere) component. Appendix B of Lewis et al. (2018) provides further details. Note that no optimisation or calibration of the river routing wave speed parameters has been attempted in this study, with values listed in Table C3 of Lewis et al. (2018) used for this initial assessment. A river routing timestep 
of $30 \mathrm{~min}$ is used, while the atmosphere and land models have a timestep of $1 \mathrm{~min}$. River routing is performed for the UK and Ireland only, with no flow directions defined for other land areas in the model domain to avoid the variable grid resolution of the land (and thereby river network) grid in these regions.

\subsection{Ocean model component}

The UK coupled system uses NEMO (Nucleus for European Modelling of the Ocean; version 3.6; Madec et al., 2020) to simulate the 3-d ocean state across the North-West European shelf with tidal and meteorological forcing. The AMM15 science configuration (Graham et al., 2018; Tonani et al., 2019) is used. The NEMO ocean grid has the same domain as the atmosphere, with regular $1.5 \mathrm{~km}$ horizontal spacing throughout (Lewis, Castillo Sanchez, et al., 2019). The model bathymetry is based on European Marine Observation and Data Network (EMODNET), with a minimum possible ocean depth of $10 \mathrm{~m}$ set in the absence of coastal wetting and drying. Daily lateral boundary conditions from a $1 / 12^{\circ}$ operational ocean forecasting system for the North Atlantic are applied, and initial conditions for 30 October 2013 are provided by the long-term AMM15 hindcast simulation described by Graham et al., (2018).

For the first time, the sensitivity of the ocean component to the use of coupled river flow simulations is assessed. Typically, for example in operational application of AMM15 and UK regional coupled research published to date, a climatological river discharge is used (Tonani et al., 2019). Figure 1a) shows 232 locations within the model domain where a daily climatology of river flows has been defined (indicated by red circles). For UK coastal points (Figure 1b), these are based on National River Flow Archive gauge observations over the period 1980-2014 while around other coastlines data are based on a pre-existing climatology averaged across 1950-2005. There is a clear imbalance between the number of discharge points around the UK relative to other areas in the model domain. For each discharge location, a river depth is specified, and a freshwater flux is applied to all ocean model levels above that depth. The climatology therefore represents some typical freshwater flux for a given day of the year, aiming to capture the main discharge locations and magnitude to establish representative near-coastal salinity and density structures.

In contrast the coupled system enables simulated river flows, representative of current conditions, to discharge into the ocean and explicitly link land to ocean processes. As the ocean and atmosphere/ land grids have their own defined land-sea masks, a one-dimensional coupling approach has been defined using OASIS whereby JULES coastal outflow locations are identified, numbered, and paired with the nearest NEMO inflow points on the ocean grid. Figure $1 \mathrm{~b}$ ) shows 842 connection points between the UK and Ireland river routing grid and discharge points on the ocean grid (indicated by blue diamonds). Given that coupled river flows are only computed for UK and Ireland rivers in this implementation, the NEMO code was modified to use a runoff coupling mask to distinguish between regions where the coupled rivers should be used while continuing to use the daily climatology elsewhere in the model domain.

\section{$2.4 \quad$ Experimental design}

This study focuses on an assessment of the performance on the UK coupled system during winter 2013/14 for simulating precipitation and its impact through the land surface and hydrological system. Three different approaches to representing river discharge into the ocean component of the coupled system are then considered, summarized in Table 1. In the fully coupled approach (CPLriv), hourly mean JULES simulated river discharge at coastal points around the UK and Ireland are mapped to the nearest NEMO ocean grid points, with climatological discharge applied elsewhere. CPLclim uses the same atmosphere-land-ocean coupled configuration but applying the climatological river discharge everywhere. In CPLnoriv, discharges around UK and Ireland are set to zero through the simulations, with climatological discharge still applied elsewhere, providing an upper bound on the magnitude of the impact of river flow quality on ocean simulations.

\section{$3 \mid$ RESULTS}

The following sub-sections present the characteristics of the simulations of winter 2013/14 relative to available observations, with focus on atmosphere (Section 3.1), land surface (Section 3.2), river flow (Section 3.3), coastal interface (Section 3.4) and near-coastal ocean (Section 3.5) components. Results are only presented from the CPLriv simulations in Sections 3.1-3.3 as the performance of atmosphere and land surface model components are essentially independent of the way that flows to the ocean are represented in each experiment (Table 1). Results from different river discharge experiments are compared in Section 3.4 and 3.5.

\section{1 | Precipitation}

The spatial and temporal evolution of monthly accumulated precipitation across the UK between November 2013 and February 2014 is shown in Figure 2. The HadUK-Grid $1 \mathrm{~km}$ gridded rainfall product based on gauge observations (Perry \& Hollis, 2005) indicates a relatively dry November but notably and increasingly wet conditions relative to climatology across much of the UK from December onwards (see Figure 3, Kendon et al., 2015 for anomaly maps). Qualitatively, the broad spatial distribution and monthly evolution of the CPLriv precipitation in Figure 2e-h is in good agreement with observations.

TABLE 1 Summary of coupled simulations assessed

\begin{tabular}{|lll}
\hline Run name & $\begin{array}{l}\text { UK + Ireland river } \\
\text { discharge }\end{array}$ & $\begin{array}{l}\text { Rest of domain river } \\
\text { discharge }\end{array}$ \\
\hline CPLriv & $\begin{array}{r}\text { JUES simulation, } \\
\text { OASIS coupled }\end{array}$ & AMM15 climatology \\
\hline CPLclim & AMM15 climatology & AMM15 climatology \\
\hline CPLnoriv & Zero flows & AMM15 climatology \\
\hline
\end{tabular}


(a)

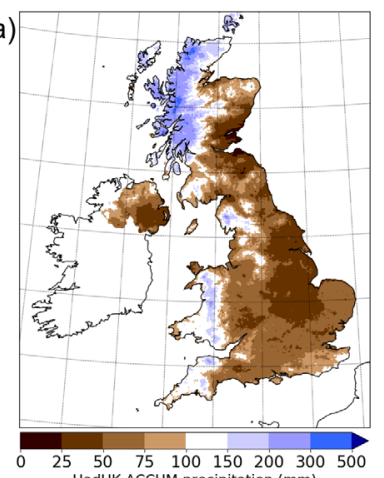

(e)

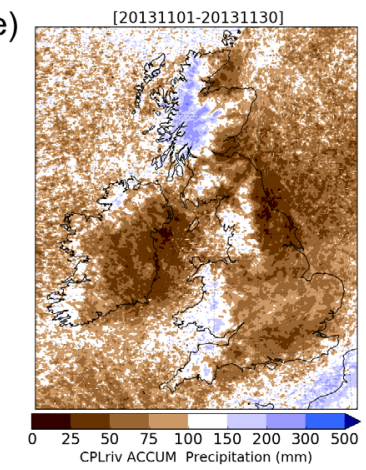

(i)

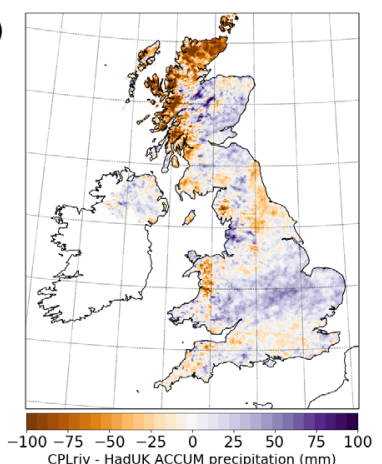

(b)

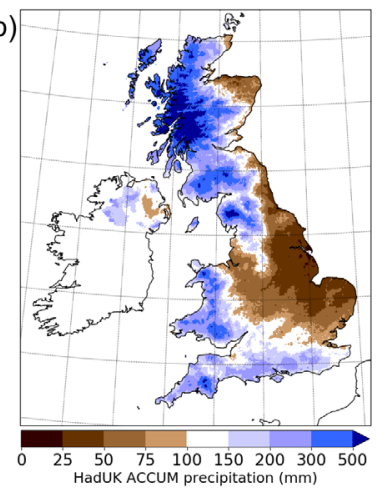

(f)

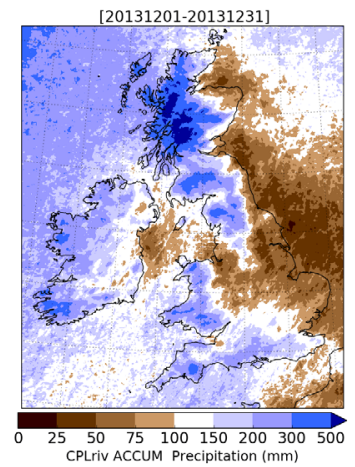

(j)

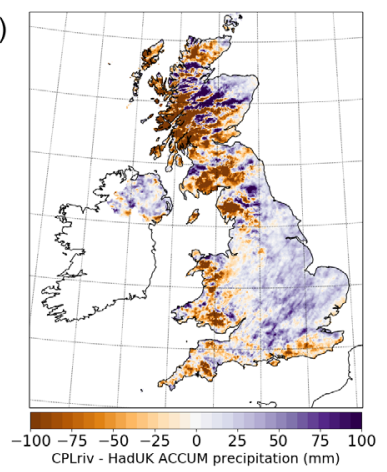

(c)

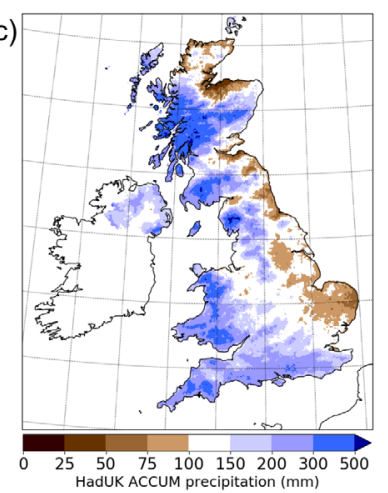

(g)

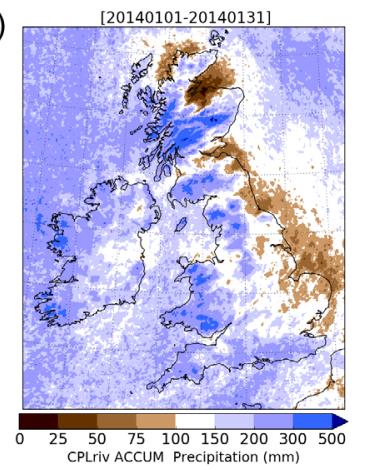

(k)

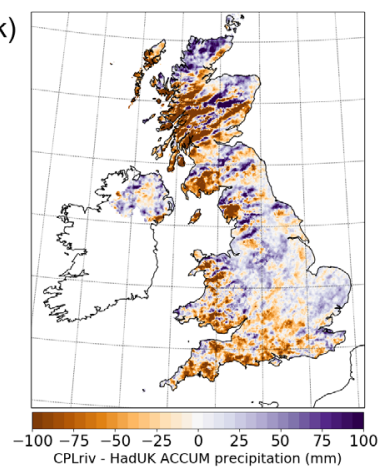

(d)

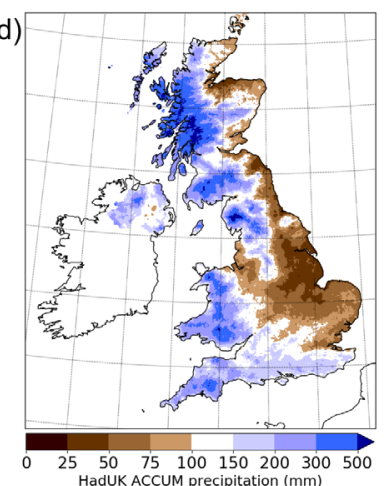

(h)

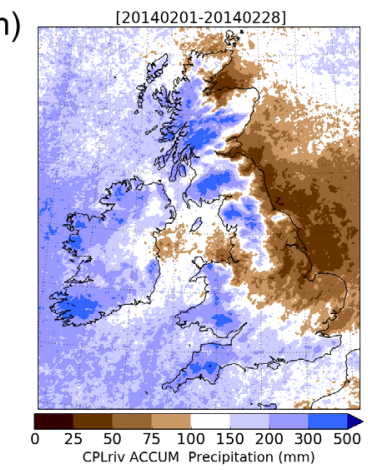

(I)

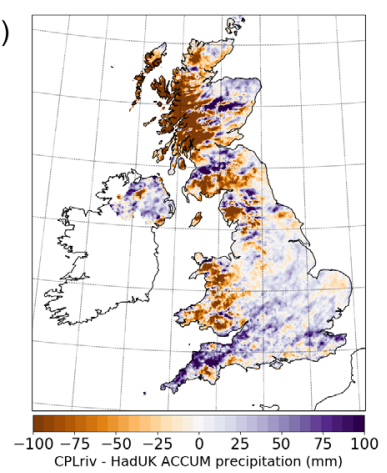

(m)

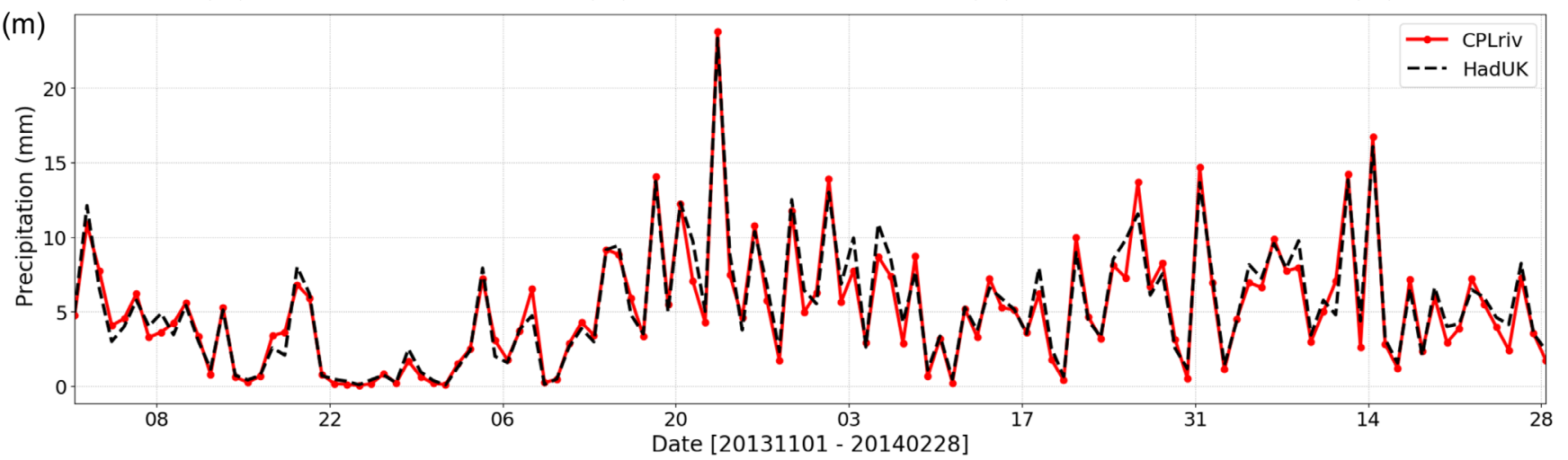

FIGURE 2 Maps of (a-d) observed and (e-h) CPLriv simulated monthly accumulated precipitation for November and December 2013, and January and February 2014. Figures (a-d) show the HadUK-grid $1 \times 1 \mathrm{~km}$ gridded gauge observed precipitation product (Perry \& Hollis, 2005). Figures ( $\mathrm{e}-\mathrm{h}$ ) show the accumulated precipitation computed from the CPLriv hourly mean rainfall rate. (i-l) Monthly accumulation differences between CPLriv and HadUK-grid precipitation computed on the HadUK-grid grid. (m) Time series comparing the CPLriv simulated and HadUKgrid observed daily mean (water day 0900-0900) precipitation across England, Scotland and Wales land points through the period

That CPLriv can reproduce observed climatological features is encouraging given that the system has no data assimilation for any component.
Differences between HadUK-Grid and CPLriv in Figure 2i-I highlight the tendency for the convective-scale Unified Model simulation to underestimate precipitation over upland areas across western UK 
(a)

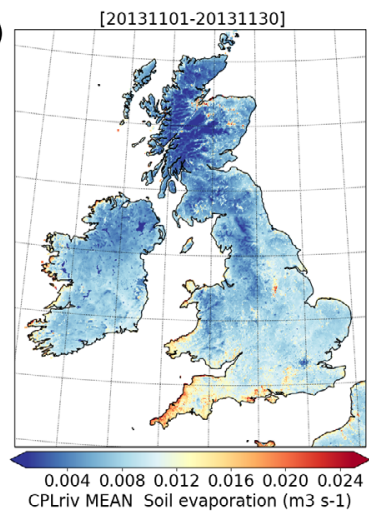

(e)

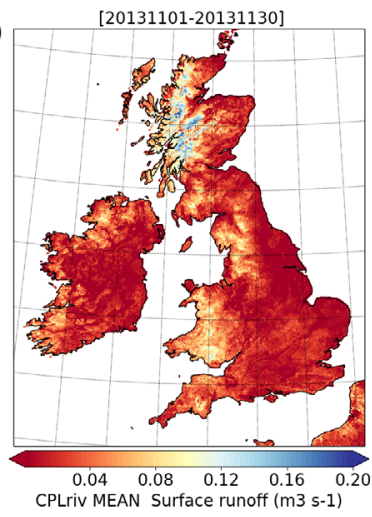

(i)

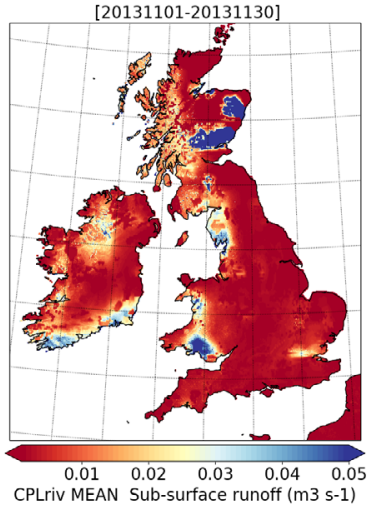

(b)

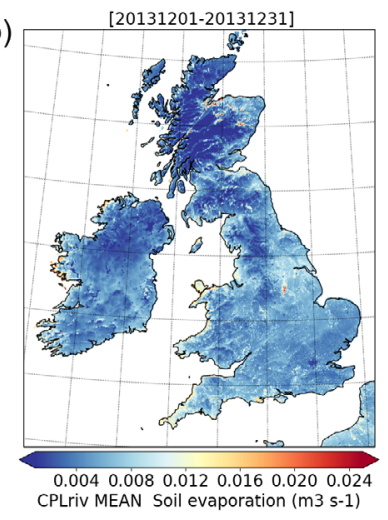

(f)

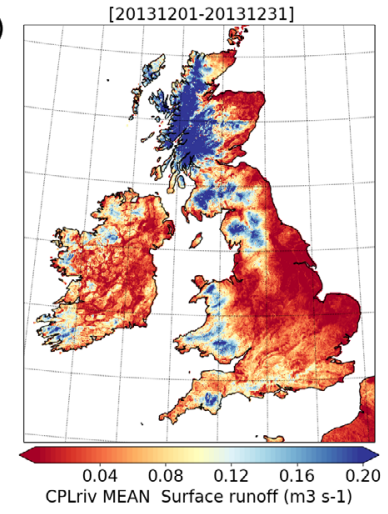

(j)

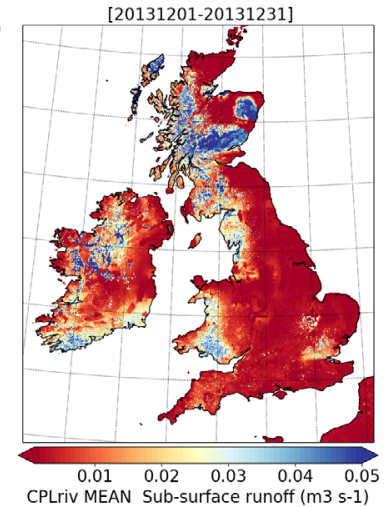

(c)

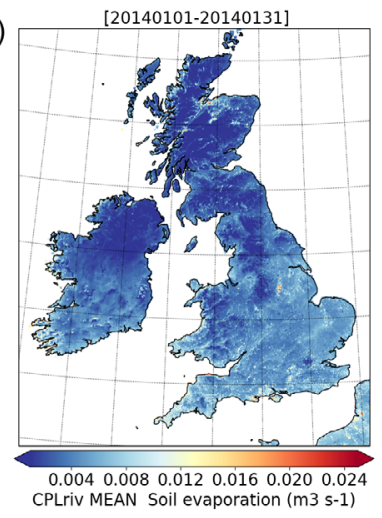

(g)

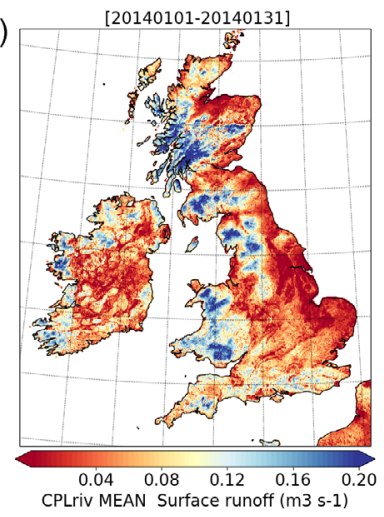

(k)

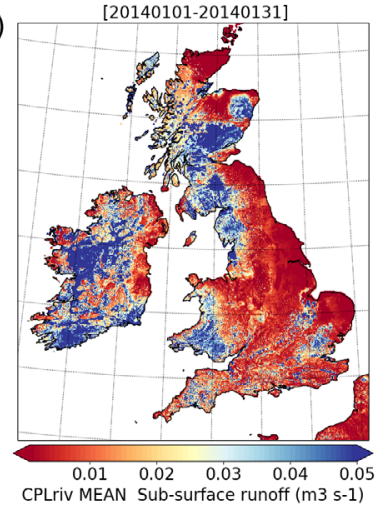

(d)

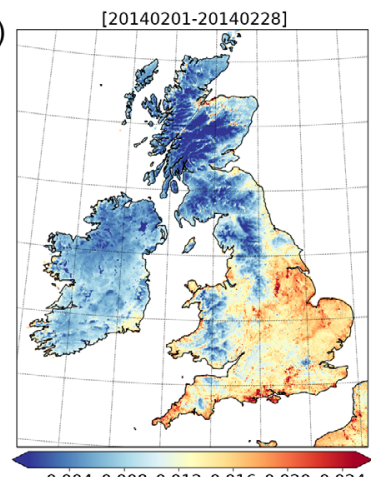

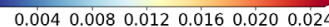
CPLriv MEAN Soil evaporation (m3 s-1)

(h)

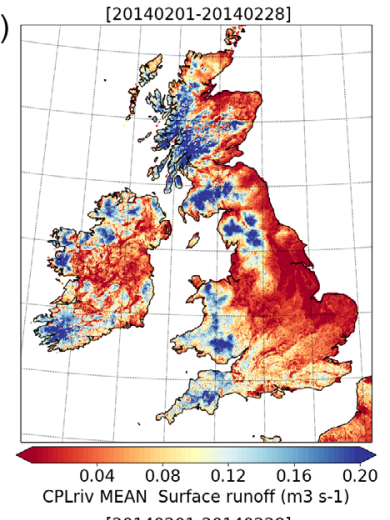

(I)

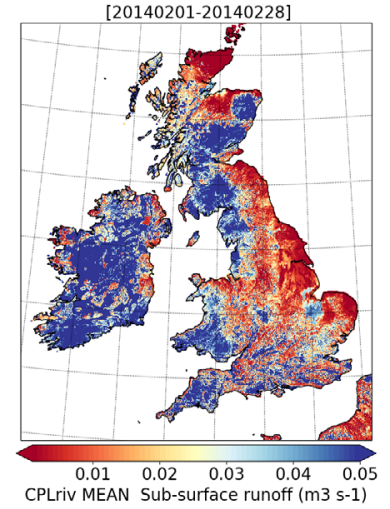

FIGURE 3 Maps of monthly mean (a-d) surface evaporation, (e-h) surface runoff and (i-l) sub-surface runoff rate simulated by CPLriv for November and December 2013, and January and February 2014 respectively. Note colour bar scales are different for each variable

while overestimating rainfall in the drier regions further east. Note CPLriv data are first interpolated to the HadUK-Grid grid for this direct comparison. Smith et al. (2015) described the considerable benefit of simulations at these resolutions for improving the representation of orographic precipitation enhancement relative to coarser-scale model grids in which local terrain gradients are smoothed out and convection is explicitly parameterized. However, these results are consistent with errors in the precipitation over orography highlighted more recently by Chan et al. (2018) for longduration Unified Model simulation using a similar configuration to that used in this study.

This tendency for CPLriv to rain too little in relatively wet regions and too much in drier regions is well illustrated by comparing the spatial SD of monthly accumulated precipitation in HadUK-Grid (Figure 2a-d) with that computed from CPLriv (Figure 2e-h). This is summarized in Table 2. The SD of CPLriv accumulated precipitation is consistently about $40 \%$ lower than for the observation-based HadUKGrid for each month during the simulation period. The benefit of future updates to the regional atmosphere configuration on model skill could therefore be simply and usefully assessed through the extent to which such stark differences can be reduced.

Time series in Figure $2 \mathrm{~m}$ compare water-day mean HadUK-Grid precipitation for England, Scotland, and Wales land areas with the equivalent simulated quantity from CPLriv. This shows good agreement through winter 2013/14 with a correlation coefficient of 0.95 (statistically significant at $95 \%$ confidence level). This provides confidence that the UK coupled system provides a robust simulation of winter precipitation, though noting spatial errors in the representation of orographic effects, which will be important in the context of hydrological simulation. 


\begin{tabular}{|llclc|} 
& November $\mathbf{2 0 1 3}$ & December 2013 & January 2014 & February 2014 \\
\hline CPLriv & $33.1 \mathrm{~mm}$ & $83.6 \mathrm{~mm}$ & $55.9 \mathrm{~mm}$ & $67.4 \mathrm{~mm}$ \\
\hline HadUK-Grid & $54.4 \mathrm{~mm}$ & $140.7 \mathrm{~mm}$ & $82.3 \mathrm{~mm}$ & $103.4 \mathrm{~mm}$ \\
\hline
\end{tabular}

TABLE 2 Spatial SD of monthly accumulated precipitation for each month during study for CPLriv simulations and HadUK-grid observations

Note: CPLriv data are interpolated to the HadUK-grid points prior to computing statistics.

\subsection{Land surface hydrological response}

The partitioning of precipitation falling on the surface through winter 2013/14 between evaporation and runoff components is shown in Figures 3 and 4. Surface runoff represents the largest flux and responds directly to precipitation as expected. December was notably wet in western Scotland and February was wettest in south-western England and Wales. The sub-surface response is more complex. Mean results for November (Figure 3e) are particularly dry over much of the UK and Ireland, but excessive runoff is apparent in some areas of Scotland and persists through the winter. As discussed by Gómez et al. (2020), the anomalously wet regions are potentially a feature of the initial soil moisture conditions interpolated from the global model analysis available for the valid time of these simulations. Mean subsurface runoff features in November are particularly smooth, indicative of an extended period of spin-up to more convective-scale forced conditions on the $1.5 \mathrm{~km}$ resolution model grid. While results are presented for the full November to February December simulation period in following sections, qualitative measures are computed for December to February only to reduce the influence of spin-up on hydrological results. Later in winter, the sub-surface runoff increases, particularly on western slopes of upland regions. This spatial distribution is driven by the slope-dependent PDM configuration introduced by Martinez-de la Torre et al. (2019).

The mean simulated volumetric water content (VWC) fraction in the upper ( $0-10 \mathrm{~cm}$ below surface) and lowest (1-3 $\mathrm{m}$ below surface) JULES soil layers is shown in Figure 4. There is a clear contrast in timescales between the upper layer being driven by instantaneous precipitation, also reflected in the surface runoff, and the lower layer driven by the accumulated precipitation over time, reflected in the sub-surface runoff evolution. The initial condition and spin-up issues highlighted in Figure 3 are not apparent in the spatial averages shown in Figure 4. By the end of February 2014, the lowest soil level holds as much water as the upper layer, and the magnitude of surface and sub-surface runoff components are more similar.

One of the challenges inherent in any assessment of the simulated land surface response to precipitation has been the limited observations of components of the terrestrial water cycle at scales relevant to the model grid. The COSMOS-UK cosmic-ray soil moisture observing system (Evans et al., 2016) was first established in 2013 and has since expanded to 52 sites across the UK (Cooper et al., 2021). During winter 2013/14 an initial four sites were active across a small part of southern England (Figure 1b). Cosmic-rays are used to derive an estimate of soil moisture representative of a horizontal area of about $0.12 \mathrm{~km}^{2}$ (order 20-times smaller than the model grid area of $2.25 \mathrm{~km}^{2}$ ) and a nominal observation depth of order $20 \mathrm{~cm}$, but which varies in time by order $5-10 \mathrm{~cm}$.

Quantitative comparison of simulated and observation-derived VWC in Figure 5 should be treated with some caution given that the model and COSMOS-UK represent different vertical and horizontal scales, and that grid box mean diagnostics represent considerable surface heterogeneity within each model grid, even at $1.5 \mathrm{~km}$ resolution. The variability of model data within a $5 \times 5$ neighbourhood of grid points surrounding each location is considered, highlighting the regions surrounding Chimney Meadows (Figure 5b) and Wytham Woods (Figure $5 \mathrm{c}$ ) to be considerably more heterogenous than those surrounding Sheepdrove (Figure 5a) and Waddesdon (Figure 5d). Comparing more qualitatively to the COSMOS-UK observations, CPLriv simulations are in relatively close alignment to observed VWC and well capture a gradual decrease in VWC during November followed by a relatively abrupt increase during mid-December. There is lower variability in VWC in both model and observations during January and February. The model timeseries show less day-to-day variability than COSMOS-UK and lower VWC than observed at three of the four locations. Yang et al. (2020) and Yang et al. (2014) reported systematic under-estimation of VWC in observation-forced JULES simulations during southern hemisphere winter and attributed this to the lack of lateral soil water flow in the JULES model. Blyth et al., (2019) found that JULES simulated evaporation tended to be excessive compared with flux tower observations, also consistent with these results. A third process deficiency consistent with this bias is a tendency for there to be insufficient infiltration of precipitation into the JULES soil column (e.g., Largeron et al., 2018; Martinez-de la Torre et al., 2019; Mueller-Quintino et al., 2016).

The closest qualitative agreement between CPLriv and COSMOSUK is found at Sheepdrove (Figure 5a). The lack of variability in VWC between adjacent model grid points in the $5 \times 5$ neighbourhood may indicate this to be a less hydrologically complex location (Cooper et al., 2020), and given the site is at $170 \mathrm{~m}$ altitude in the Chiltern Hills, there may be a more limited role for lateral flows here.

This analysis indicates that a more extensive assessment of the simulated JULES soil moisture state at $\mathrm{km}$-scales for more recent periods would be of considerable value. This would need to look at a more recent simulation period to make use of the more extensive and multi-annual COSMOS-UK observations across the 52 sites available today in order to better characterize, understand and improve the representation of soil moisture processes across a broader range of meteorological and hydrological conditions, and across a broader range of soil and land use types. This analysis could usefully form the basis for further optimisation of land surface parameters, and assessment of 
(a)

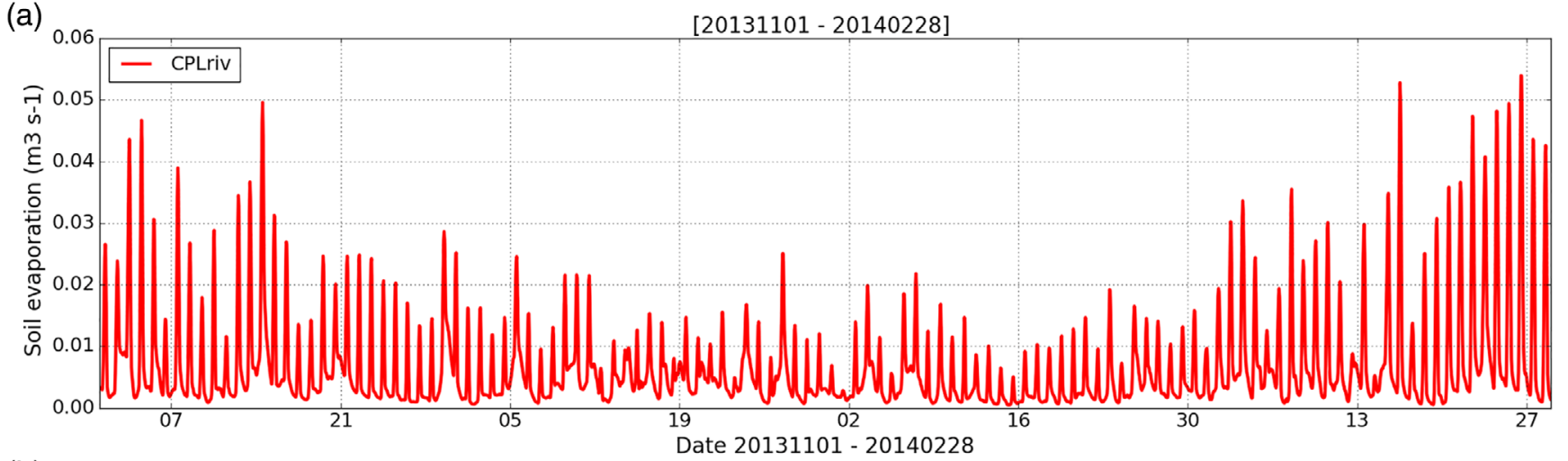

(b)

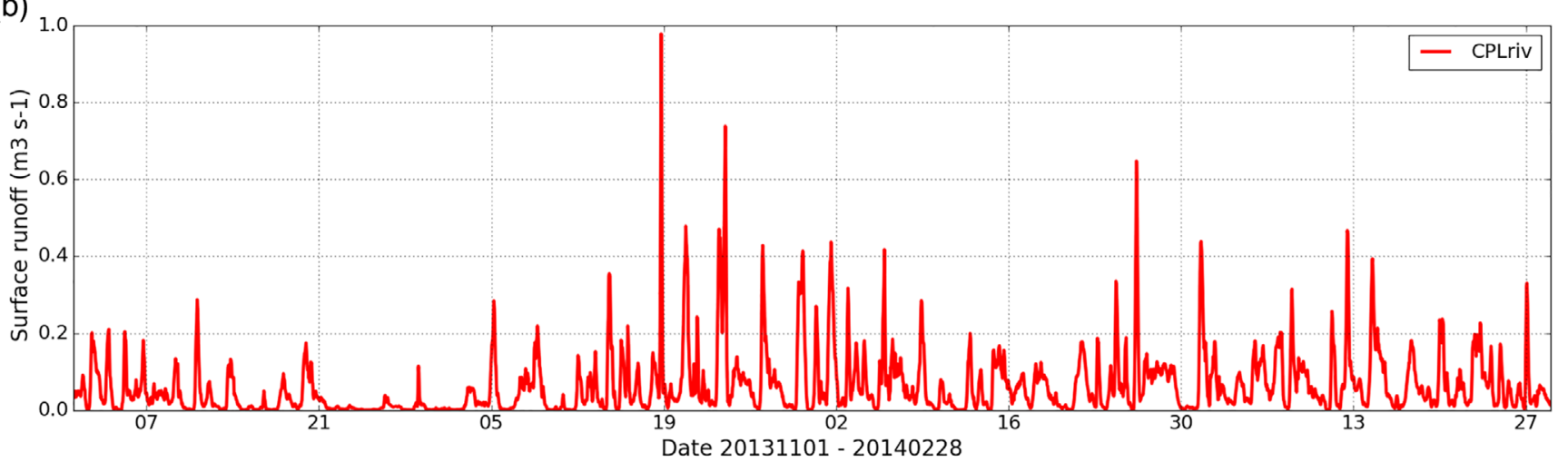

(c)

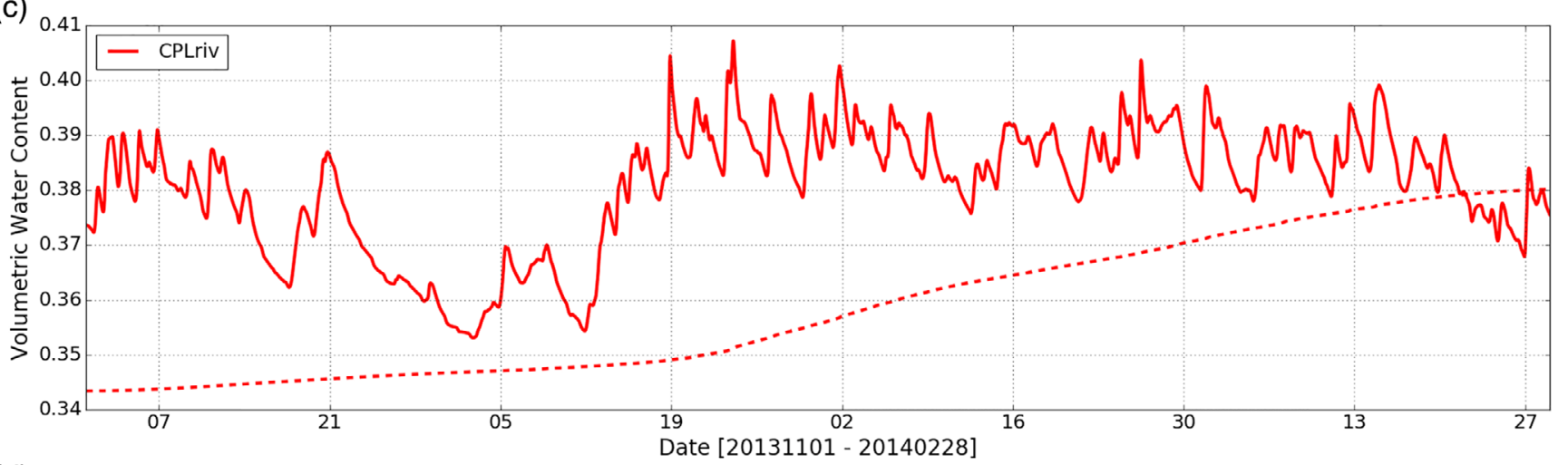

(d)

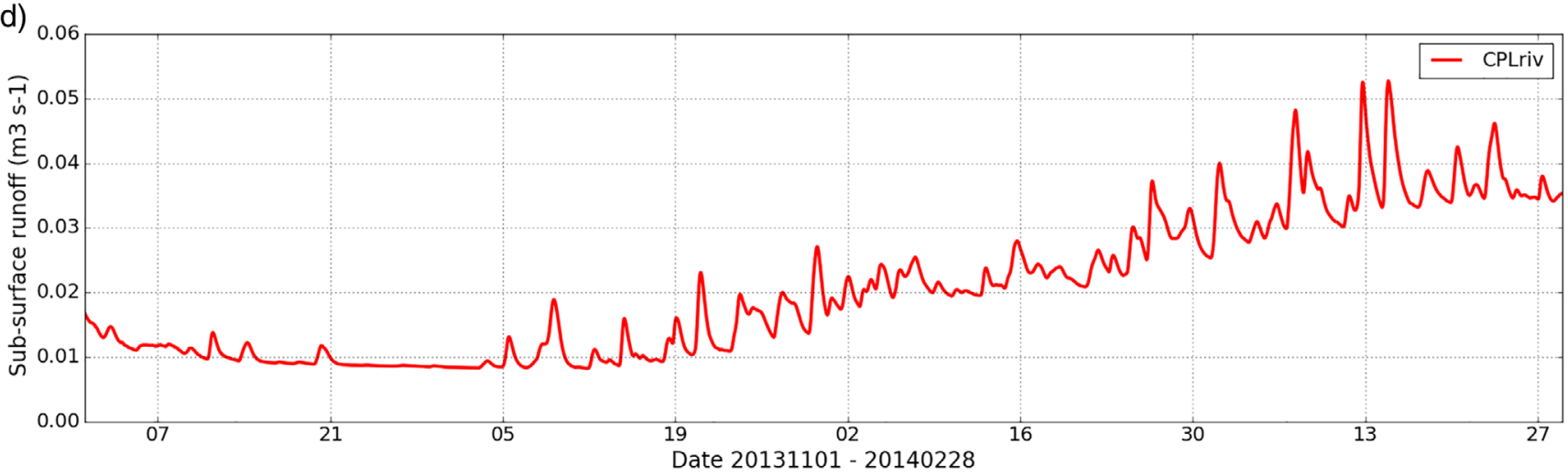

FIG URE 4 Timeseries of spatially averaged daily mean simulated (a) soil evaporation, (b) surface runoff, (c) volumetric soil moisture content of the upper (0-0.1 $\mathrm{m}$ depth) soil level (solid) and lowest (1-3 $\mathrm{m}$ depth below surface) soil level (dashed), (d) sub-surface runoff across England, Scotland and Wales land points in the CPLriv coupled system during winter 2013/14 
(a)

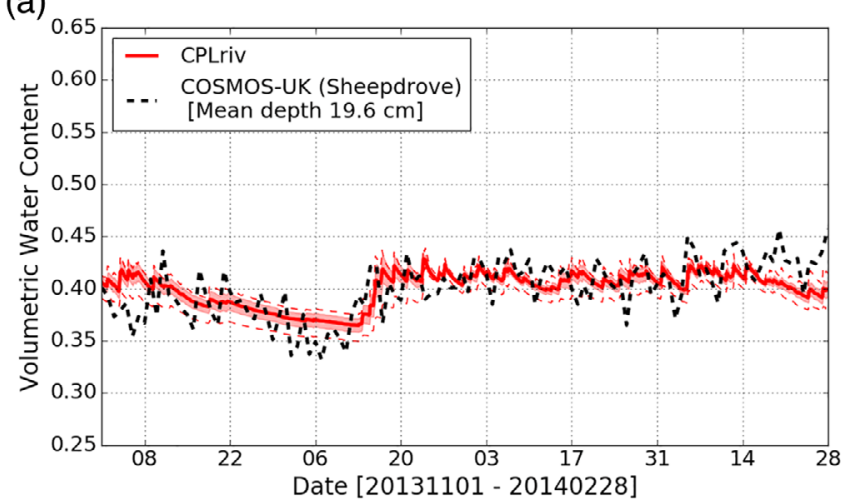

(c)

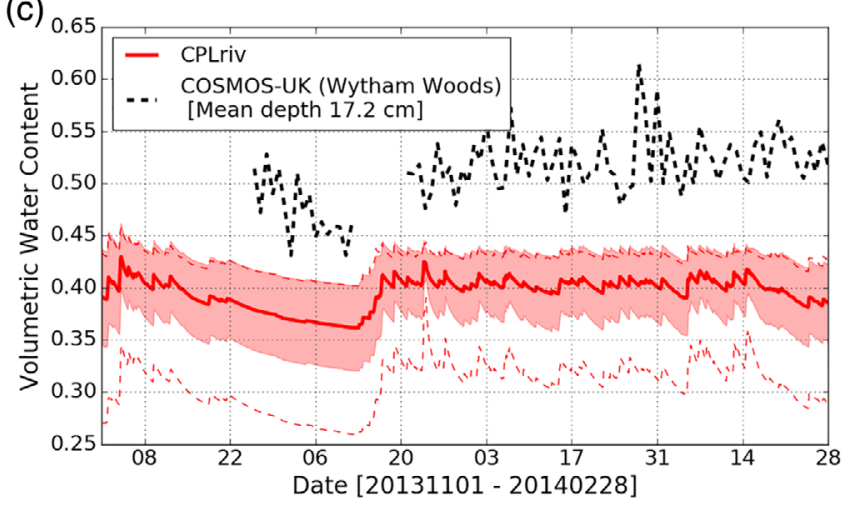

(b)

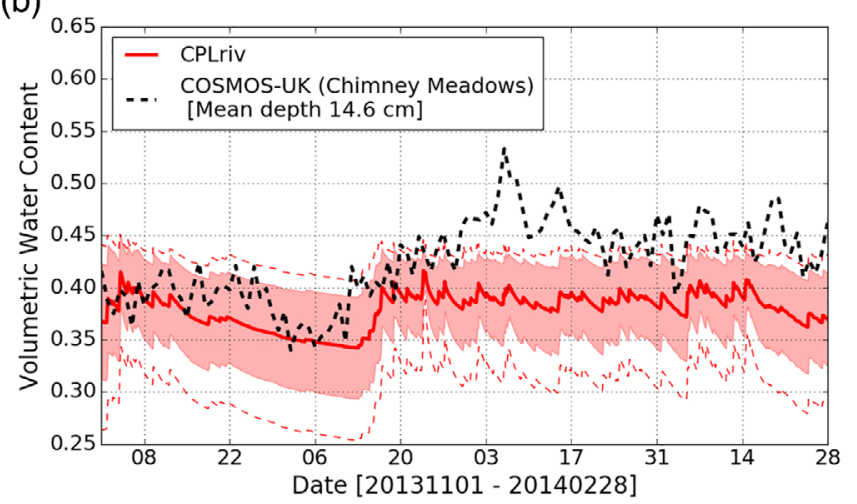

(d)

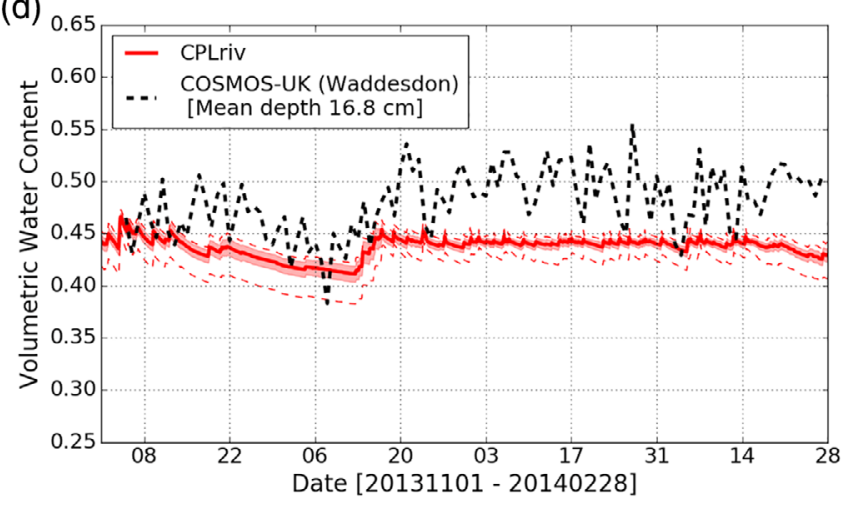

FIGURE 5 Timeseries showing CPLriv simulated total volumetric water content in the top 2 soil levels (to depth $35 \mathrm{~cm}$ below surface) through November 2013-February 2014. Plots (a-d) are for points marked 1-4 in Figure 1 respectively. The mean value in a $5 \times 5$ neighbourhood of grid points nearest each location is shown as a solid line, with one SD about that value shaded. The minimum and maximum model values in the neighbourhood are shown as dashed line time series. Also plotted are available daily mean COSMOS-UK cosmic-ray derived volumetric water content estimations for each location (Stanley et al., 2020). The mean typical depth for which these observations are considered appropriate through the period for each site is listed in each figure legend

the variability and accuracy of VWC on each land surface tile within a land surface model grid cell.

\section{3 | River flow}

Relative to diagnostics of soil moisture processes, river discharge is a well observed part of the terrestrial water cycle. Figure 6 shows a first-order check on the typical magnitude of simulated and observed flows through the study period across parts of the river routing network, indicating generally good qualitative distinction between higher and lower flow regions in CPLriv. Daily mean river flow gauge observations are provided by the UK National River Flow Archive (NRFA). Summary bias and Nash-Sutcliffe efficiency (NSE) metrics for the simulated river flow in CPLriv between December 2013 and February 2014 are compared with observations at 154 gauges in Figure 7. This set of gauges includes the 146 UK Benchmark Network sites (UKBN2; Harrigan et al., 2018), selected to favour relatively natural flow regimes and good hydrometric data quality, together with those of the 13 catchments assessed by Martinez-de la Torre et al. (2019) not included in UKBN2.
Given that the system is driven by simulated precipitation, most land surface parameters have been optimized for NWP applications, and no tuning has been applied for river flow parameters, Figure 7a) is encouraging in that the simulated flows have small biases relative to many gauge locations (99 locations where the bias is within $10 \mathrm{~m}^{3} \mathrm{~s}^{-1}$, 88 locations where the bias is within $20 \%$ of the peak observed flow magnitude). More substantial biases can be seen in south-eastern England where CPLriv flows are overestimated relative to observations. This is characterized as a groundwater dominated region - a process not represented in the free drainage approach of the JULES configuration used in these simulations. Batelis et al. (2020) described the application of a new groundwater flow boundary parameterization in JULES which may improve flow simulations in such regions. CPLriv can also be seen to overestimate flows in central Scotland, which are likely attributable to excessive sub-surface runoff and a poorly initialized soil moisture state.

While a NSE value of one represents a perfect simulation of the observed time series, a NSE value of zero indicates that the simulation provides no better prediction of the observed time series than the observed mean, and might be considered a minimal requirement of a useful river flow simulation. This target is only met for 69 (order 45\%) 
(a)

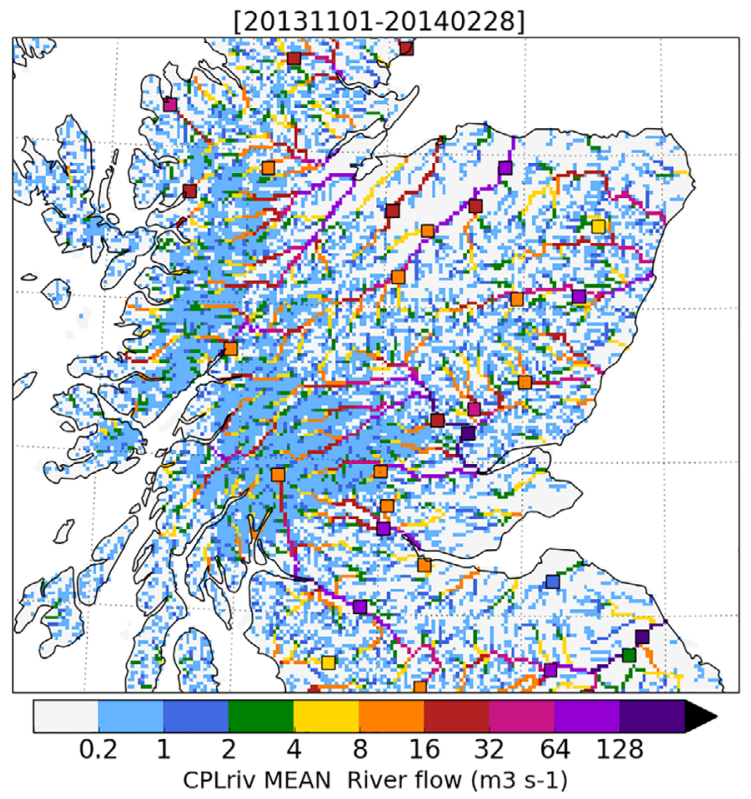

(c)

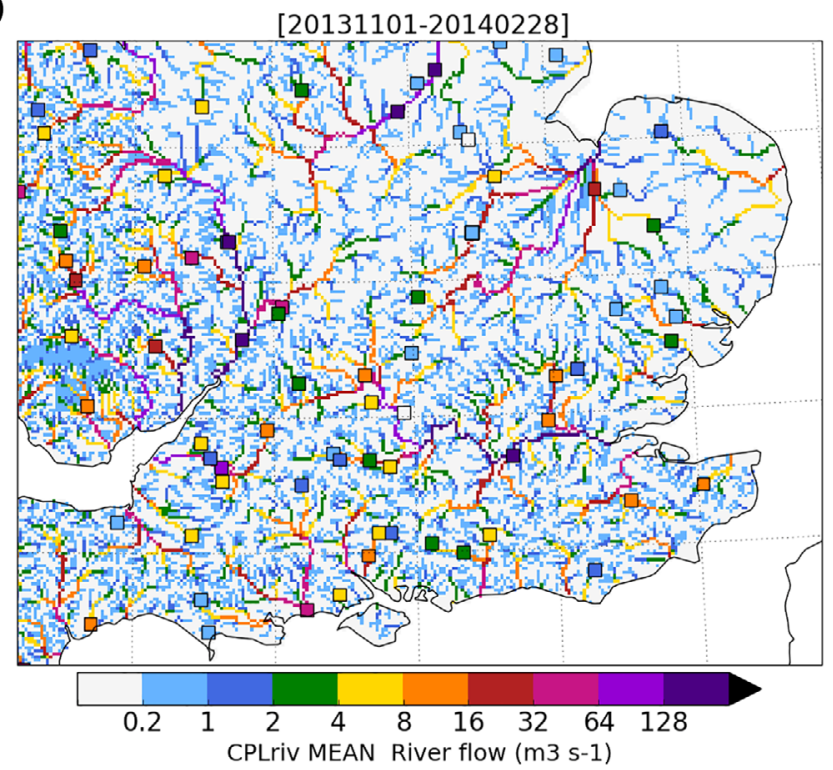

(b)

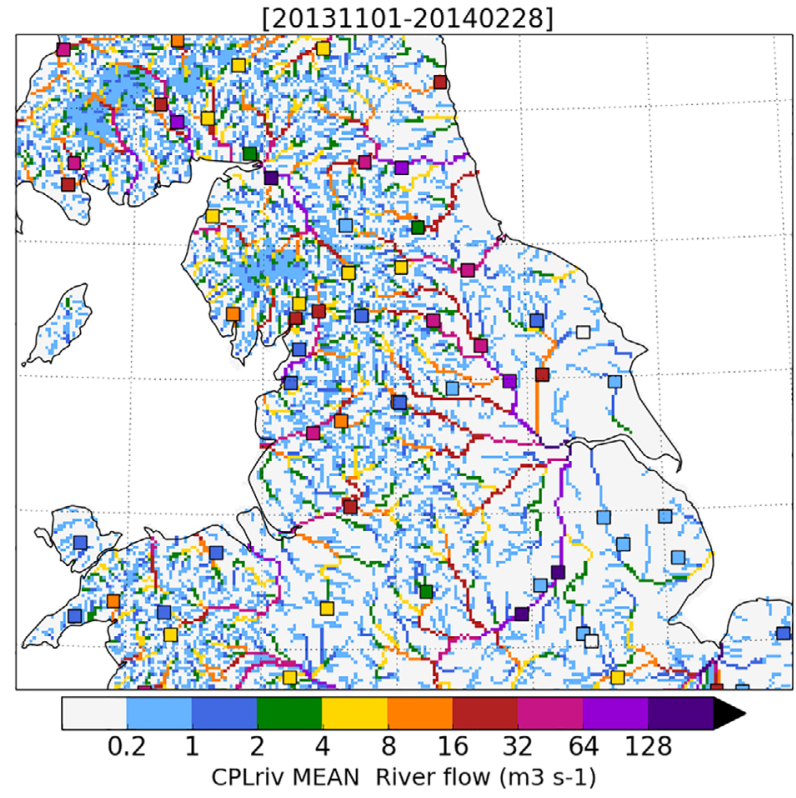

(d)

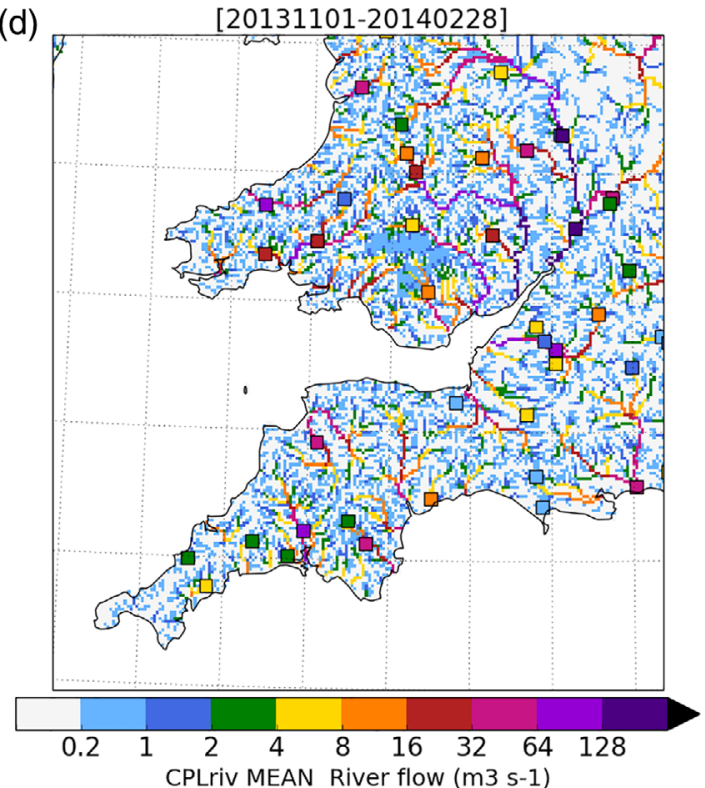

FIGURE 6 Maps of mean simulated river flow speeds between November 2013 and February 2014 for selected sub-regions of the UK (see Figure 1). Mean observed flows for the same period at gauges in the National River Flow Archive (NRFA) UK benchmark (UKBN2) dataset are plotted using the same colour scale as shaded square symbols

of the 154 gauges considered, with 10 locations having a summary NSE value greater than 0.5 . Figure $7 \mathrm{~b}$ ) shows that the locations with best NSE values tend to be where observed flows are largest, and therefore typically of most interest from the perspective of the broad scale hydrological response in CPLriv. The relatively low number of gauge locations for which NSE exceed zero, noting these are computed over only 3 months of data, indicates that there is clear need to focus research effort on improving the magnitude and timing of river flow simulations in CPLriv.

Figure 8 provides a more direct illustration of the simulated and observed daily mean flows through winter 2013/14 for four of the gauges considered by Martinez-de la Torre et al. (2019). The Tamar, Tay and Severn gauges are among the locations where CPLriv has largest low bias relative to observations (Figure 7a) while CPLriv is biased high at Thames, attributable in part to missing groundwater storage. For reference, results from observation-driven hydrological model simulations of Grid-to-Grid (G2G; Bell et al., 2018; Bell et al., 2007) and DECIPHeR (Coxon et al., 2019b) are shown. These indicate plausible best simulated results. DECIPHeR is a 100 -member ensemble, illustrating the influence of parameter uncertainty on the model hydrological results for a given observed input. Both $G 2 G$ and DECIPHeR are driven by $1 \mathrm{~km}^{2}$ gridded daily precipitation fields 
(a)

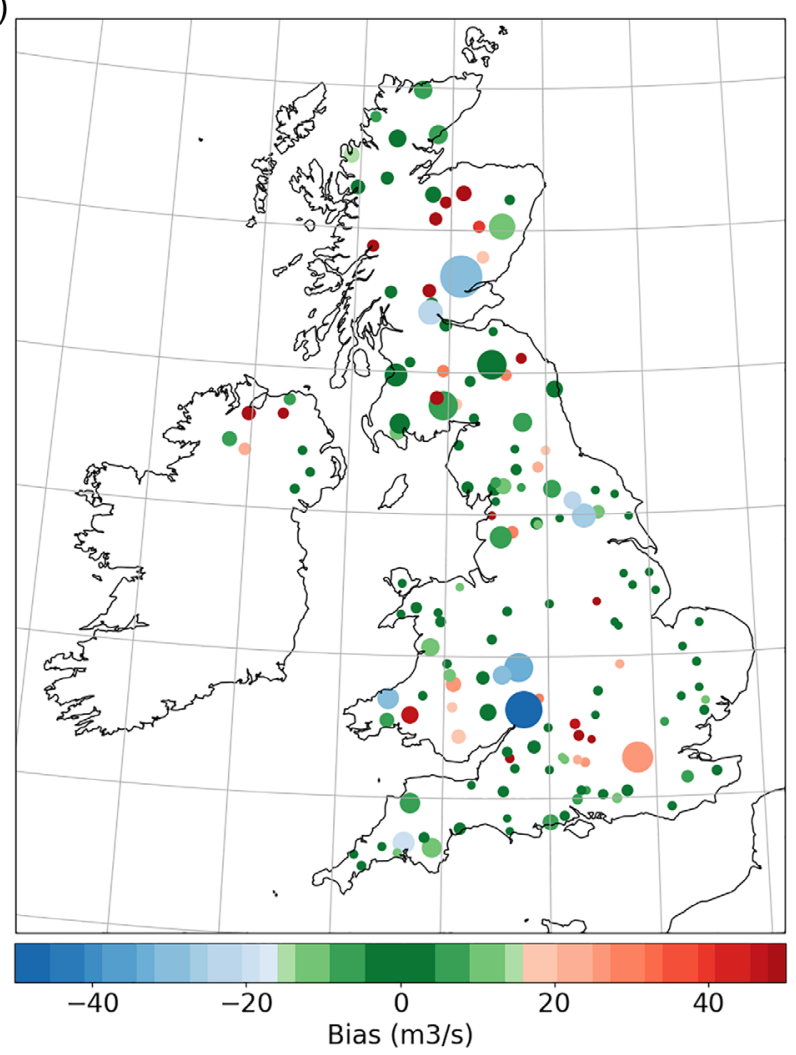

(b)

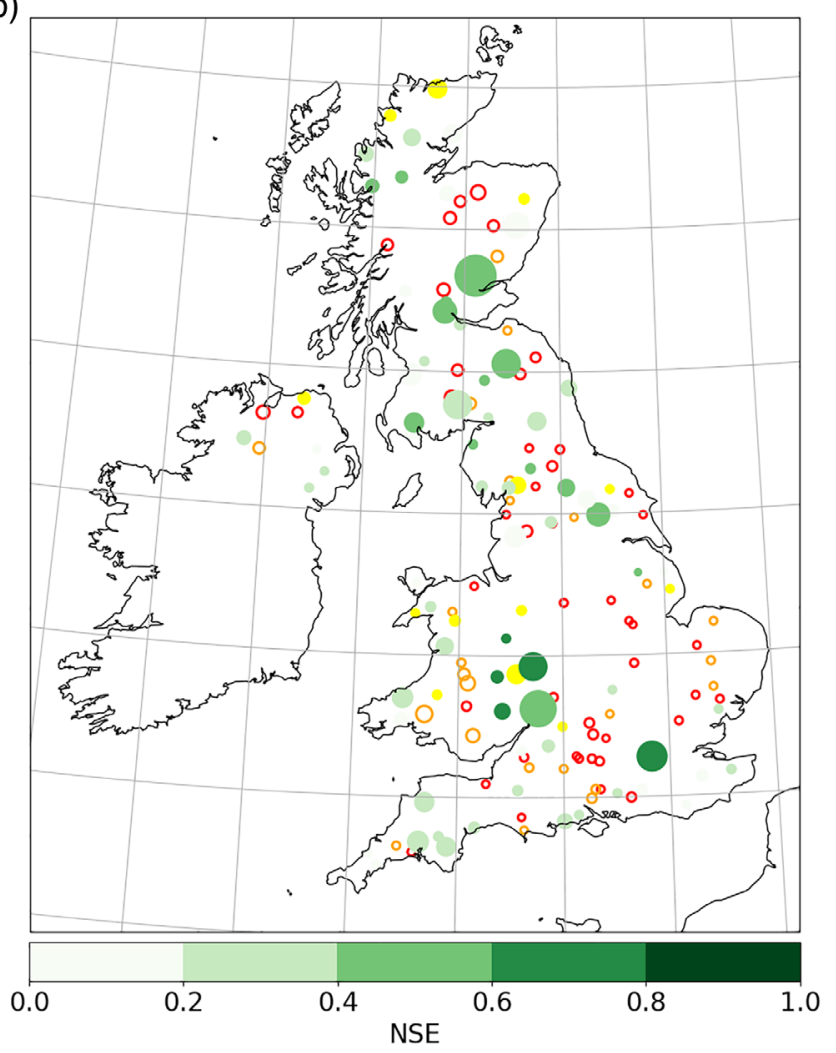

FIGURE 7 Summary of (a) bias [MODEL-OBS] and (b) Nash-Sutcliffe efficiency (NSE) metrics comparing observed and simulated river flow at selected National River Flow Archive (NRFA) locations. Only data from December 2013, January 2014 and February 2014 are included here to avoid any spin up impacts at the start of the simulation period. The size of circles is representative of the maximum observed flow during the period. In (b), green shaded circles show where NSE $>=0$, with shading indicated by the colour scale. Yellow filled circles show where $-1<=$ NSE $<0$, orange unfilled circles where $-10<$ NSE $<-1$ and red unfilled circles where NSE values less than -10 are computed for the evaluation period

derived from rain gauge observations. G2G was driven by a corrected monthly potential evaporation derived from $5 \mathrm{~km}^{2}$ gridded temperature observations (Rudd et al., 2017), while as described by Coxon et al. (2019a), the DECIPHeR ensemble was driven by daily potential evapotranspiration data derived at $1 \mathrm{~km}^{2}$ by Robinson et al. (2017). The G2G model underpins operational flood forecasting in the UK and has therefore been optimized to represent peak flow conditions across a wide range of UK hydrological regimes (Anderson et al., 2019; Pilling et al., 2016). Unlike JULES or G2G grid-based routing, DECIPHeR represents a different model architecture that uses hydrological response units to represent land heterogeneity and a semi-distributed approach to flow routing (Coxon et al., 2019a).

The CPLriv flows vary too slowly with time compared to observations and G2G or DECIPHeR, although the broader-scale variability on weekly to monthly timescales is more consistent. Largeron et al. (2018) found that changes to the JULES infiltration could lead to much more responsive river flow simulations than found using the standard configuration scheme used in this study. For three of the four locations presented in Figure 8, the slower variability of CPLriv simulated flows contributes to an under-prediction of peak flows. Results are often but not always within the range of solutions provided by the DECIPHeR observation-driven ensemble. While there is a clear need for further tuning and improvement of the CPLriv flow results, this is outside the scope of this study. As discussed further in Section 4, improving the CPLriv river flow predictions requires a combination of coupled and uncoupled model development and assessment approaches. This includes studies of the performance of the current RAL1 configuration and the impacts of incremental updates through further JULES enhancements on longer (i.e. multi-annual) simulations. Weedon et al. (2015) demonstrated the value of crossspectral time-series analysis to simultaneously assess the impact of future system changes across temporal scales of interest.

\subsection{Discharge to ocean}

Coupled modelling approaches enable terrestrial hydrological simulations to directly impact the near coastal ocean. The time series of accumulated river discharge into the ocean around UK and Ireland coastlines in CPLriv (Figure 9) is consistent with previous results for precipitation, soil moisture and river flow variables of the system, declining through November and early December 2013 before 
(a)

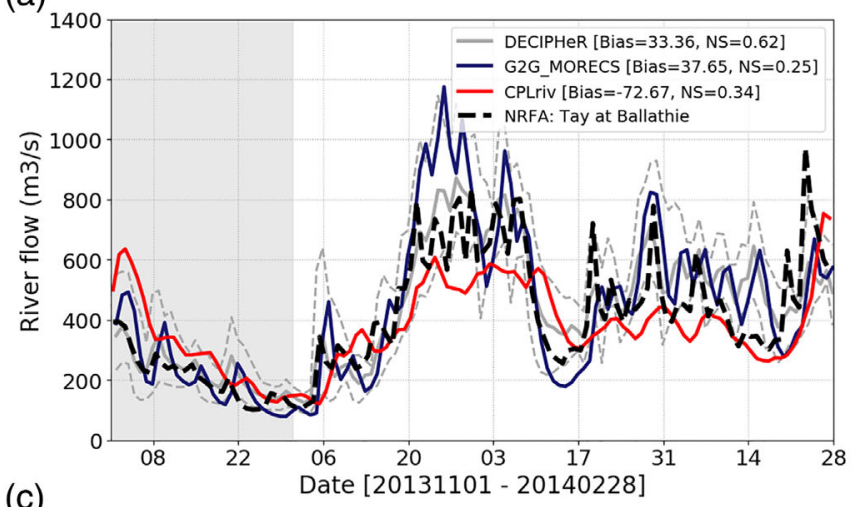

(c)

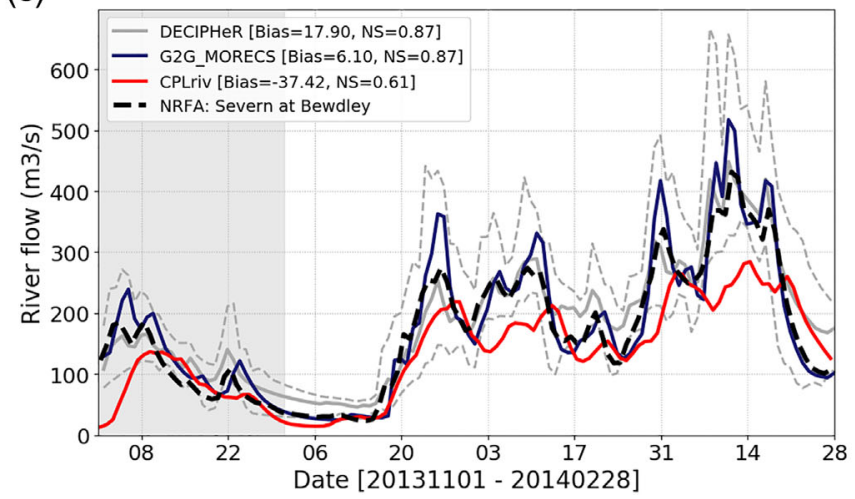

(b)

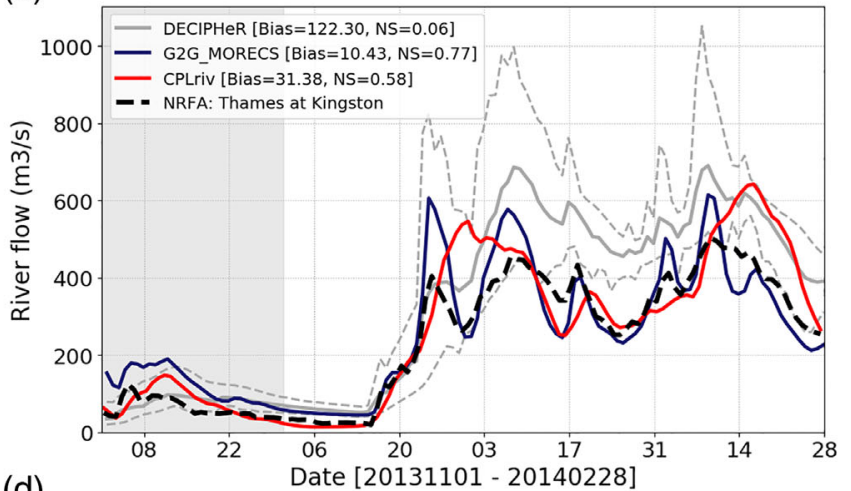

(d)

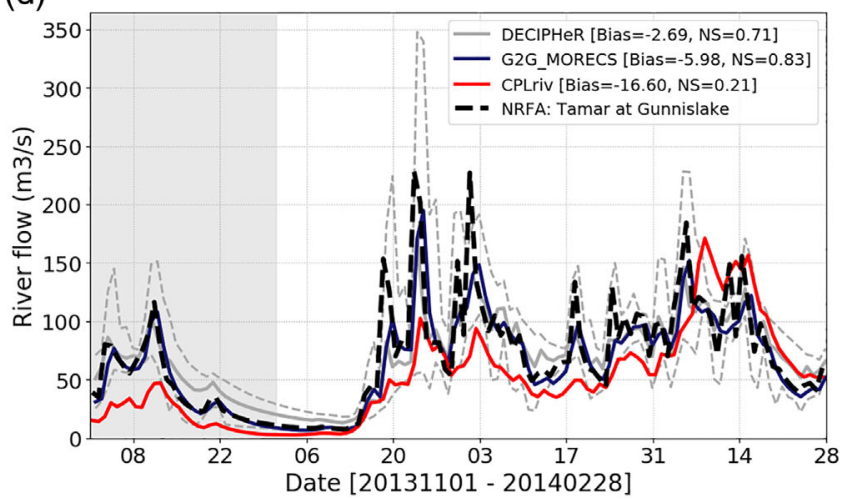

FIGURE 8 Timeseries of observed (black dashed) and simulated (red) daily mean (0900-0900) river flow at selected gauge locations from those assessed by Martinez-de la Torre et al. (2019) between November 2013 and February 2014. Mean bias (model-Obs) and Nash-Sutcliffe efficiency metrics, computed from 1 December 2013, are listed. River flows from the G2G in dark blue (Bell et al., 2018) and DECIPHeR in grey (Coxon et al., 2019b) hydrological models driven by the same observed precipitation and observation-based potential evaporation are also shown as a reference. As DECIPHeR is a 100 -member ensemble dataset, the ensemble mean is plotted along with maxima and minima simulated daily flows

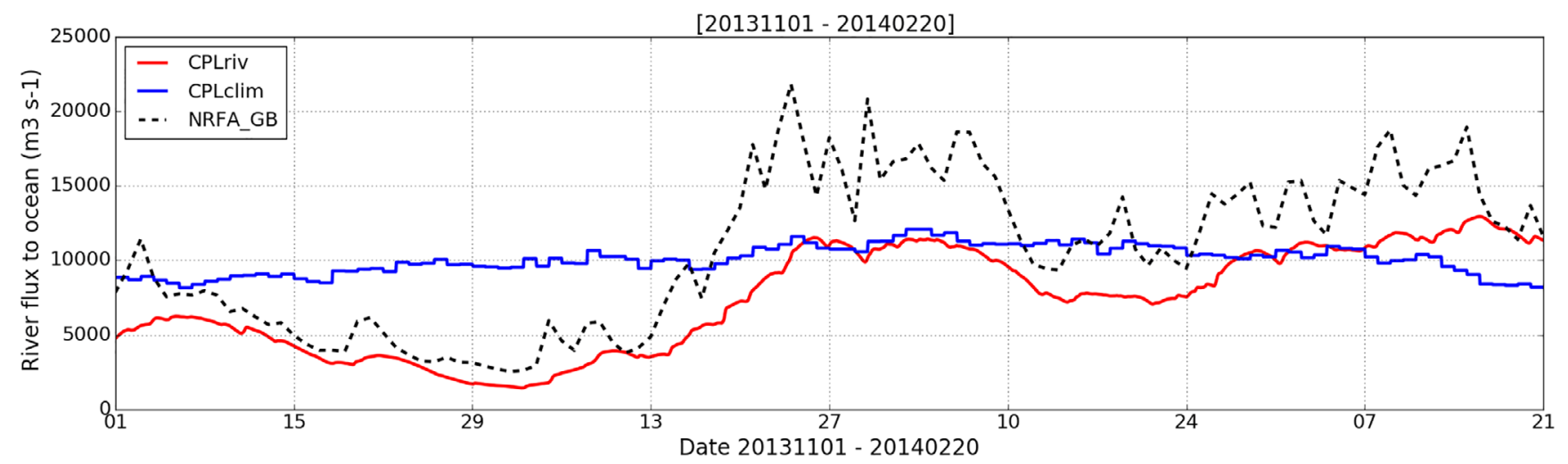

FIGURE 9 Timeseries of accumulated discharge from land to ocean around England, Scotland and Wales coastlines during winter 2013/14 in the CPL simulations (red), as assumed in the AMM15 ocean model climatology (blue) and a UK National Runoff Series estimated from gauge observations by the National River Flow Archive (black dashed line; Marsh et al., 2015)

reaching maxima over a period of around 3 weeks in late December to mid-January 2014 and again in February. This is consistent with the evolution of the UK National Runoff Series (UKNRS), an observation-derived estimate of the discharge from England, Scotland, and Wales coastlines. This is calculated as described by Marsh et al. (2015) by accumulating the total observed runoff from NRFA gauged catchments and using simulations of the $G 2 G$ model to account for flows from remaining ungauged catchments. $G 2 G$ data accounts for around $37 \%$ of the England-Wales-Scotland outflow product. CPLriv results are up to $50 \%$ lower than UKNRS during the 
December/January peak and, consistent with Figure 8, show less dayto-day variability than the UKNRS reference. Figure 9 also shows the equivalent discharge in the climatological river flows used to force the ocean in CPLclim simulations. CPLriv total values only begin to exceed CPLclim during February whereas the relatively stationary winter climatology is likely an overestimate of the observed coastal discharge during the first part and an underestimate during the latter part of winter 2013/14. In the context of a first evaluation of a more coupled approach to the UK water cycle however, Figure 9 provides further reassurance that the order of magnitude of discharge from CPLriv and its temporal variability are broadly representative.

\section{5 | Coastal ocean response}

The sensitivity of the coupled NEMO ocean surface salinity to the freshwater flux imposed at the coastline is summarized in Figure 10. Monthly mean salinity difference maps show the extent of regions of freshwater influence around the UK and Ireland. CPLriv is generally less fresh than CPLclim, consistent with the relatively reduced discharge (Figure 9). Largest differences, exceeding 2 psu, due to lower flows in CPLriv are apparent for outflow regions from the Thames (consistent with Figure 7b), Bristol Channel (associated with lower flows from the river Severn; Figure 7c) and Humber Estuary (fed by the rivers Ouse and Trent; Figure $6 \mathrm{~b}$ ). Timeseries of region mean surface salinity in Figure 10e) show that the CPLnoriv ocean surface becomes increasingly saline with time, reaching a mean difference of nearly 0.2 psu over the 4-month simulation period. This exceeds the CPLriv and CPLclim variability during the period. CPLnoriv becomes well mixed through the ocean depth, resulting in considerably less temporal variability due to tidal and meteorological forcing than CPLriv or CPLclim. By default, river discharge is applied in NEMO with zero salinity (i.e. fresh water). This is a simplifying assumption and additional source of uncertainty. Sensitivity to input salinity and parameterizations of estuarine mixing processes should be explored in future.

The mean SST response (Figure 11) is typically within $0.1 \mathrm{~K}$ around the UK coastline, with more complex and less coherent spatial patterns of SST differences due to the river forcing than for salinity. Figure 11e) indicates that the SST sensitivity (even for CPLnoriv results) is considerably smaller than the magnitude of near-coastal SST simulation errors. Those errors can be mainly attributed to missing ocean model processes such as coastline wetting and drying or meteorological or tidal forcing errors (Tonani et al., 2019). Analysis of SST results at some coastal buoys around the UK (not shown) does indicate more localized responses to differences in river forcing associated with the representation of specific storms in CPLriv and their absence in CPLclim. While outside the scope of this paper, and noting sensitivities are within the observational error, this provides some encouragement that nearcoastal simulations can be improved through further optimisation of the river flows in CPLriv. (a)

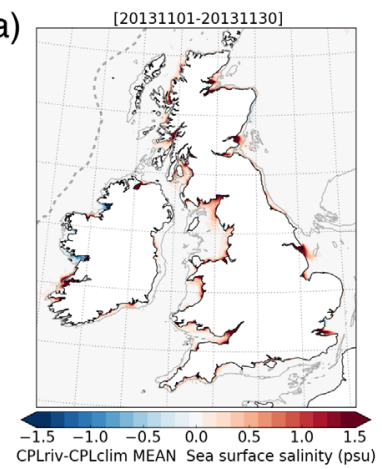

(b)

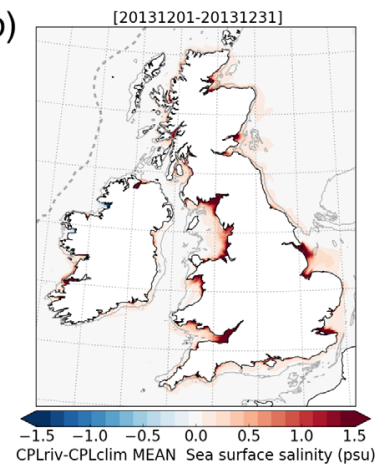

(c)

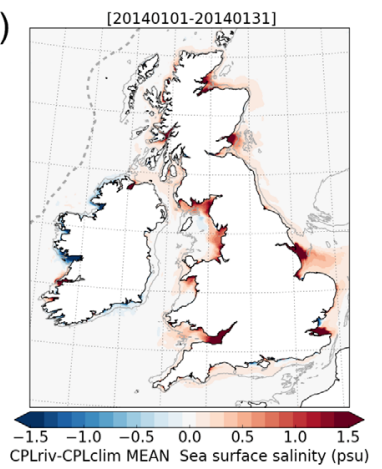

(d))

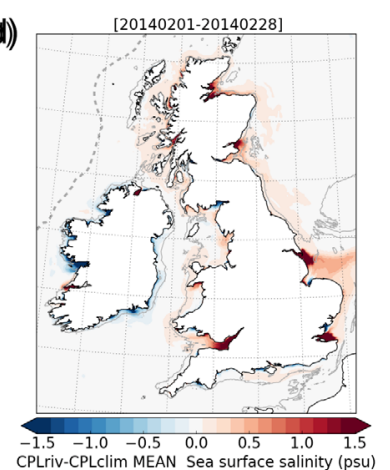

(e)

[20131101 - 20140228] -1_478851_708

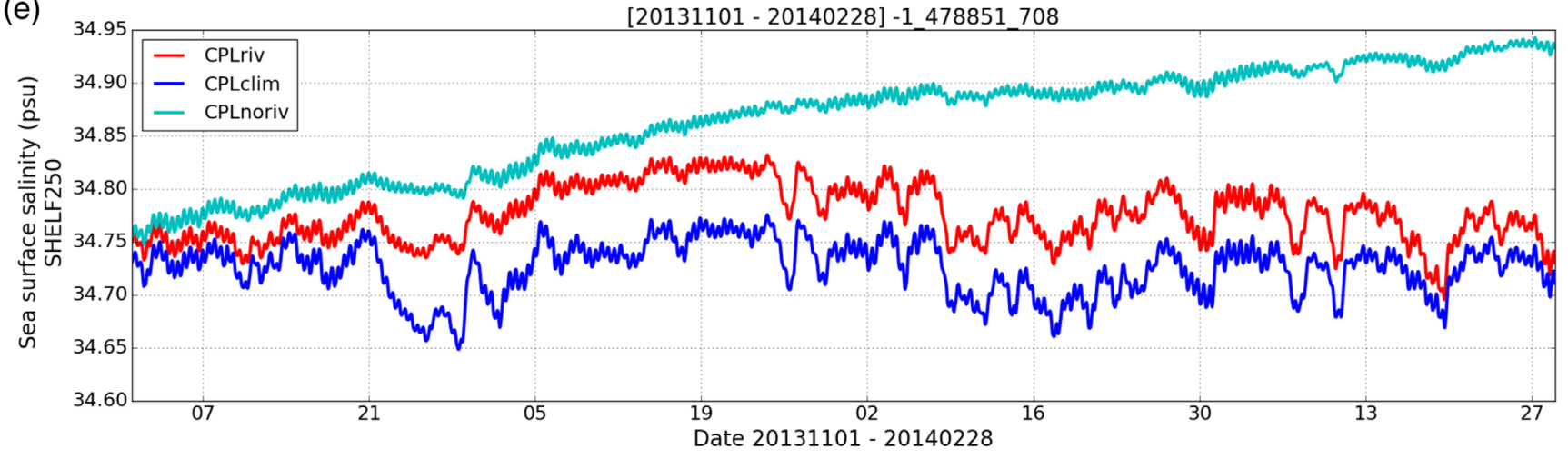

FIG URE 10 Monthly mean differences of (a-d) sea surface salinity simulated by CPLriv and CPLclim through winter 2013/14. (e) Timeseries of average sea surface salinity in the region with bathymetry shallower than 250 m around UK and Ireland coasts simulated by CPLriv, CPLclim and CPLnoriv configurations 
(a)

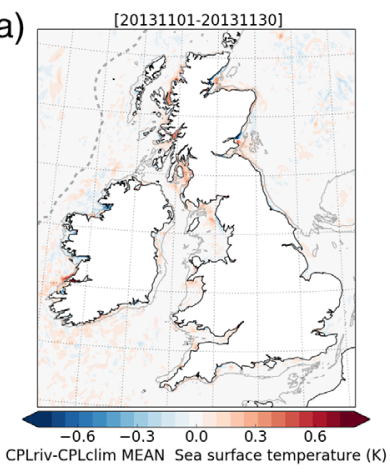

(b)

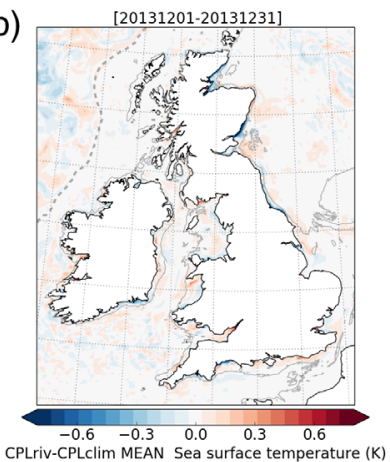

(c)

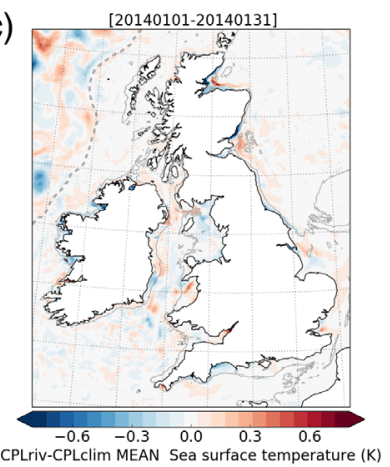

(d)

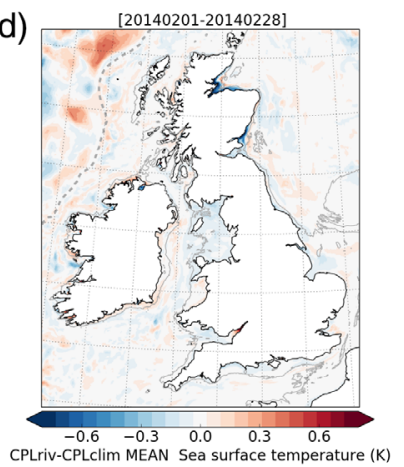

(e)

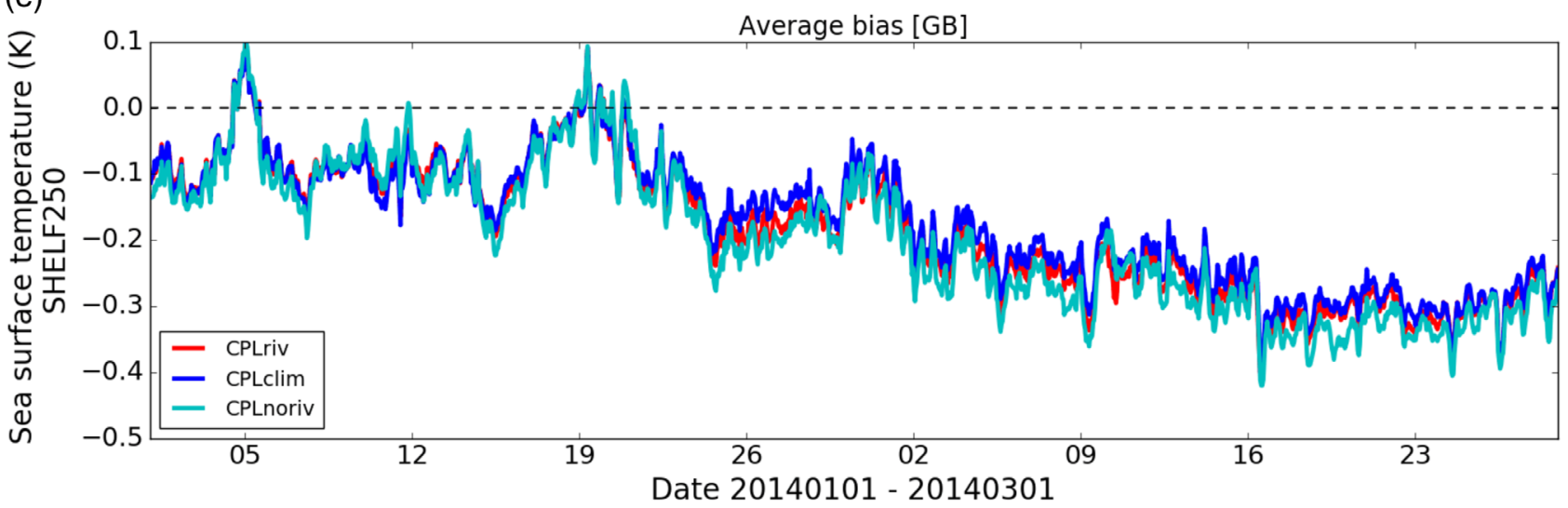

FIGURE 11 Monthly mean differences of (a-d) sea surface temperature simulated by CPLriv and CPLclim through winter 2013/14.

(e) Timeseries of average bias (model-observation) between simulations and observed SST by near-coastal buoys in the region with bathymetry shallower than $250 \mathrm{~m}$ around UK and Ireland coasts for CPLriv, CPLclim and CPLnoriv configurations during January and February 2014

The sensitivity of simulated vertical profiles of ocean salinity and temperature through winter 2013/14 at the L4 buoy location off the south-west England coast (Figure 1) is shown in Figures 12 and 13 respectively. Vertical ocean profile observations are provided by CTD sensor measurements operated weekly by Plymouth Marine Laboratory (Smyth et al., 2009).

Results for 9 December (Figure 12a and 13a) show some indications of the ocean state at depth spinning up from a common initial condition with climatological river inputs. The CPLclim profile matches the observed inversion relatively well, but is overall too fresh by around $0.25 \mathrm{psu}$, consistent with a relatively high river discharge relative to observations through November and December. The CPLriv and CPLnoriv results by contrast are well mixed throughout and more closely match observed salinity in the upper $20 \mathrm{~m}$. The CPLnoriv salinity remains relatively constant through this period and tends to be too saline (and too cool) even at $50 \mathrm{~m}$ depth and completely misses the observed near-surface freshwater induced inversion. CPLriv and CPLclim have more similar profiles, but there are encouraging signals that the shape of CPLriv salinity profiles better match observations than CPLclim and have closer agreement to observed near-surface values. Such differences may be particularly important when assimilating profile information for example (King et al., 2019), and merits a more rigorous assessment of the impact of simulated river inputs in a full ocean assimilation experiment in near future. The temperature profiles in Figure 13 also show clear structural differences between simulations, consistent with the differences in salinity, although the magnitude of differences between CPLriv and CPLclim is typically within $0.1-0.2 \mathrm{~K}$.

\section{4 | DISCUSSION}

This study provides a first assessment of the hydrological performance of a whole system simulation of the water cycle using a UKfocussed regional coupled system at $\mathrm{km}$-scale. In common with the evidence provided by Durnford et al. (2017), the vision for a more integrated approach to water cycle prediction is a technical reality. A free-running $\mathrm{km}$-scale coupled simulation of the UK water cycle across atmosphere, land and ocean components has been demonstrated and run successfully, producing broadly representative results across all components for winter 2013/14.

\section{1 | Recommendations for model development and evaluation}

These results highlight that many limitations and scientific challenges will need to be overcome before the UK-focussed regional coupled system could be applied with confidence for hazard prediction applications across timescales. To best address those limitations, a blended 
(a)

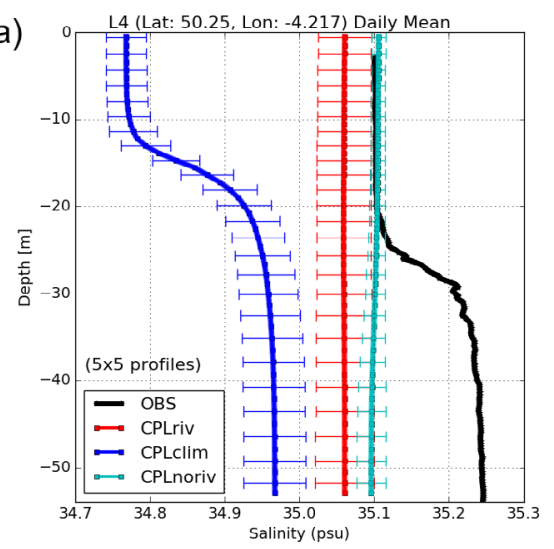

(d)

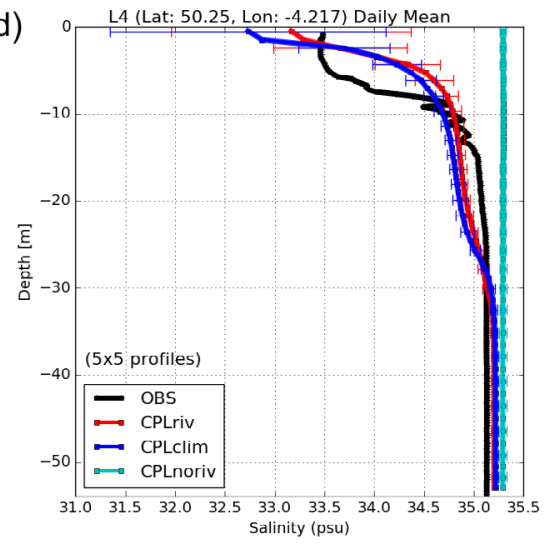

(b)

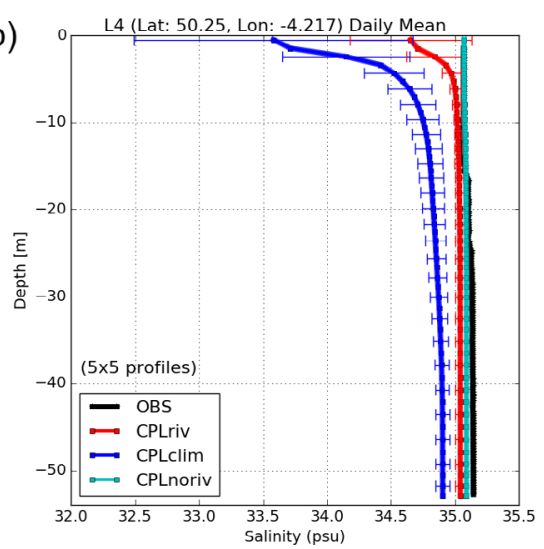

(e)

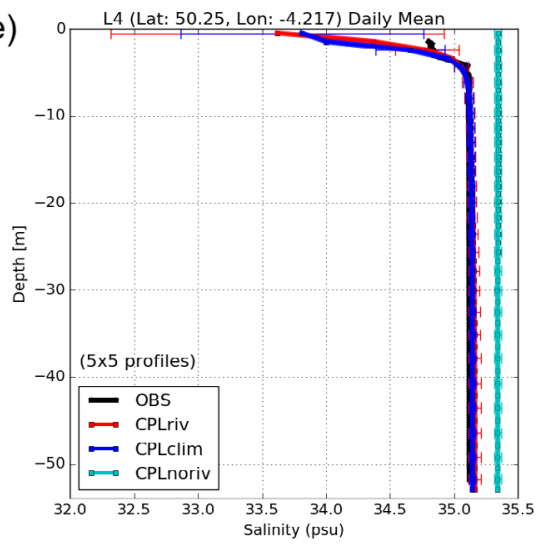

(c)

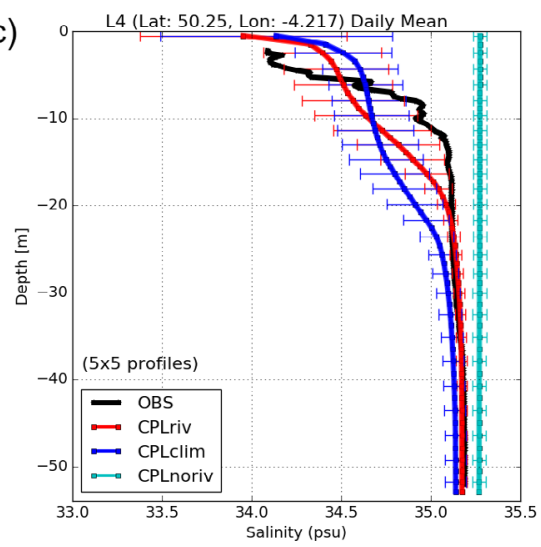

(f)

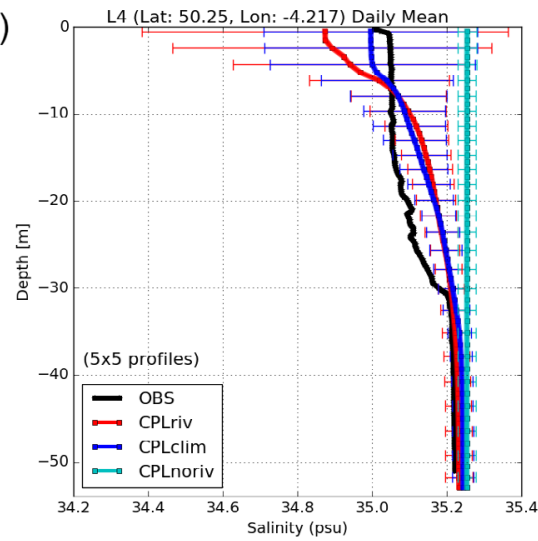

FIGURE 12 Vertical profiles of observed and simulated ocean salinity at the L4 ocean buoy location (see Figure 1) on (a) 9 December, (b) 17 December 2013, (c) 14 January, (d) 20 January, (e) 29 January, (f) 10 February 2014. Daily mean profiles are computed from $5 \times 5$ grid points nearest to the observation point, with one SD indicated by error bars

approach is required for model development and evaluation. On the one hand, as demonstrated by Deacu et al. (2012) in the Canadian context, and advocated by Flack et al. (2019) in the context of UK predictions, system improvements should be realized with an end-to-end assessment to avoid building dependence on either compensating errors or necessary bias or calibration corrections through a modelling chain. However, the current study also illustrates that there remains a need to focus on addressing model errors at a component (and subcomponent level), with ability to isolate and test model parameterisations and assumptions for key processes with known inputs (e.g., observed forcing, idealized simulations) and assessed against observed outputs. This highlights the technical imperative for environmental predictions systems to be designed as flexible modelling frameworks, rather than monolithic and intractable systems of increasing complexity. By supporting a variety of traceable experimental design and levels of uncoupled to fully coupled predictions, such frameworks provide a means to link from process-level understanding and improvement through to enabling routine evaluation of the impact of those changes on other components of the system. It cannot therefore be sufficient to have an ambition to be 'end-to-end', but to support 'component-to-system' evaluation and development, and this is where further value of working across environmental modelling disciplines and taking more whole-system approaches can be realized.

These and similar CPLriv simulations will therefore need to be revisited routinely to assess the impact of future component model developments, that will originate through detailed assessment and research to optimize regional atmosphere, land surface and ocean configurations (e.g., Bush et al., 2020; Graham et al., 2018), on the whole-system performance. However, it is encouraged that as far as practical, such process-level assessments are conducted with a view to readily being applicable to improving the UK regional coupled system, for example through simulation studies focussed on common domains, model grids, and use of supporting mapped data. While the winter 2013/14 period provides a high-profile and high-impact period for initial demonstration of the regional coupled approach to water cycle prediction for the UK, further evaluation experiments will also be required to cover a broader range of climatological conditions, including those associated with convectively dominated intense summer rainfall and prolonged dry periods.

\section{2 | Hydrological focus for atmosphere configuration development}

It has been shown that he simulated precipitation in CPLriv is representative of observations at national scale, yet there are clear biases in its spatial distribution even on monthly timescales with relatively low accumulation over steeper terrain across western UK and too much rainfall propagating further east. While the benefit of $\mathrm{km}$-scale resolution atmosphere modelling for improving the representation of 
(a)

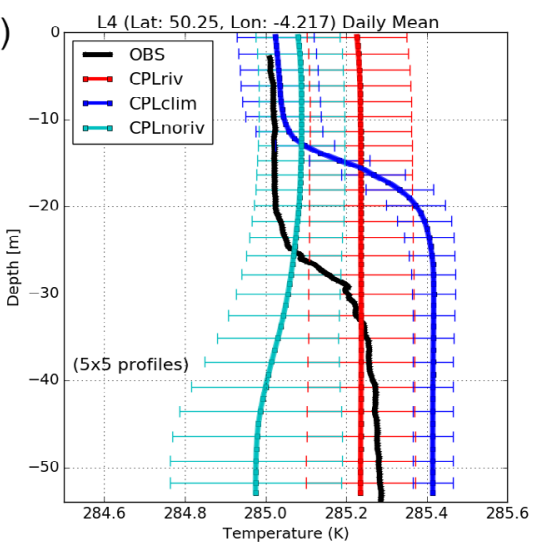

(d)

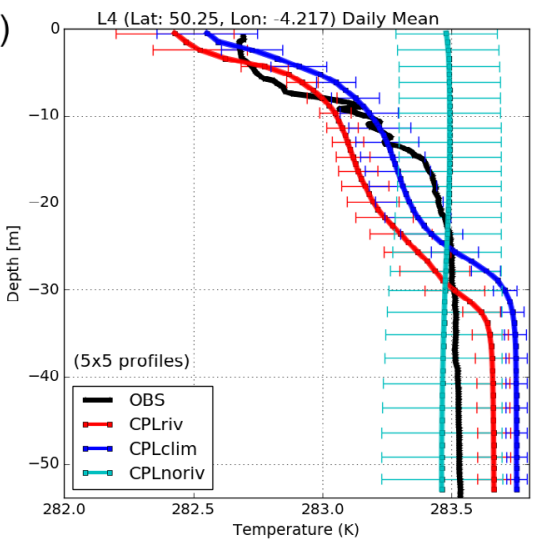

(b)

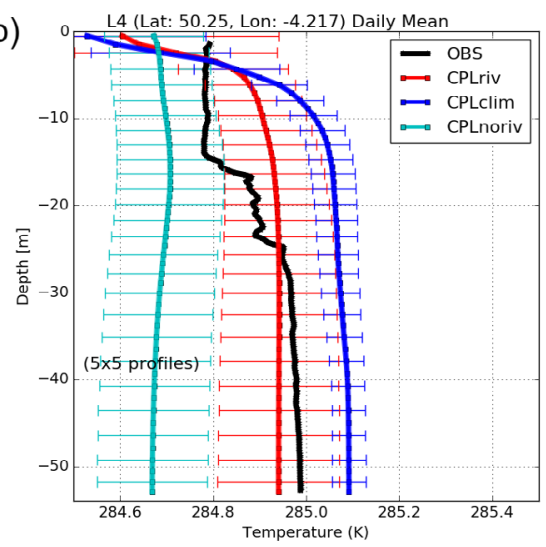

(e)

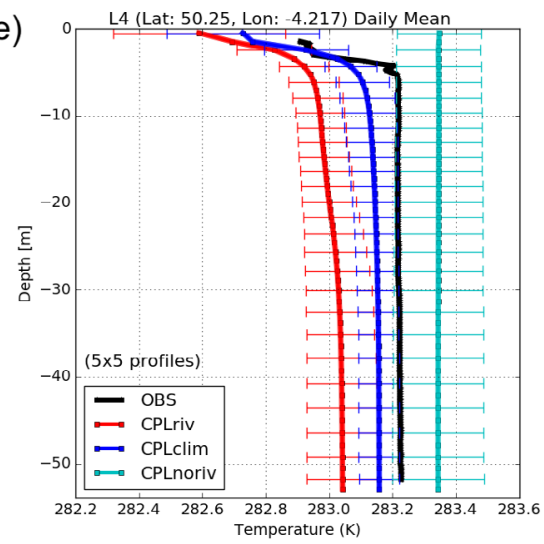

(c)

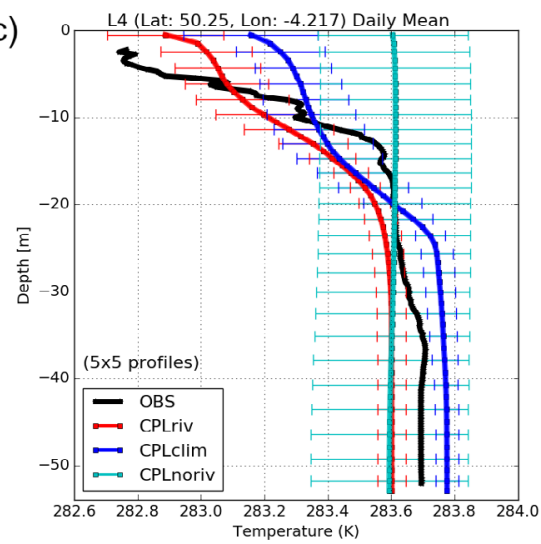

(f)

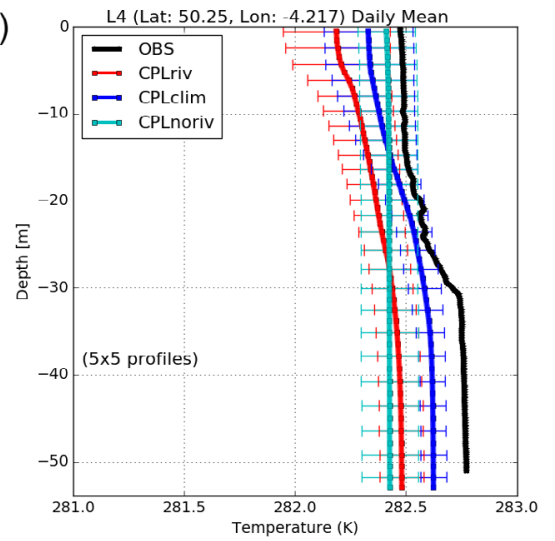

FIGURE 13 Vertical profiles of observed and simulated ocean temperature at the L4 ocean buoy location (see Figure 1) on (a) 9 December, (b) 17 December 2013, (c) 14 January, (d) 20 January, (e) 29 January, (f) 10 February 2014

orographic rainfall has been well established (e.g., Roberts et al., 2009; Smith et al., 2015), this study shows lower skill for precipitation over steep terrain than indicated for operational regional NWP results for the UK at $1.5 \mathrm{~km}$ resolution by Smith et al. (2015). The west-east bias pattern is however consistent with the results for winter precipitation of a regional climate (i.e. non-assimilating) application of the UM over Scotland at this scale by Chan et al. (2018). This merits further investigation and improvement, both to identify the role of data assimilation in the better operational NWP performance and to assess whether there are additional influences such as changes to model physics, domain extent or global boundary conditions which impact precipitation biases and can lead to an improved treatment in future RAL configurations. An experiment is proposed to assess the land surface response to parallel free-running and assimilative NWP meteorology driving JULES over a prolonged period, to better understand the extent to which simulated river flows are degraded by the absence of assimilation in CPLriv at present.

\section{3 | Linking forced to coupled land surface model development and evaluation}

The CPLriv hydrological configuration effectively translates the recommendations of Martinez-de la Torre et al. (2019), obtained from an assessment of observation-driven JULES simulations (1991-2000) at 13 gauges of interest, to a national-scale system. Martinez-de la Torre et al. (2019) presented river flow simulations biased low relative to observations (typically between $-30 \%$ and $-10 \%$ bias) with NSE metrics in the range 0.59-0.85. In common with Martinez-de la Torre et al. (2019), key land surface processes for improvement remain a balance between:

- Reducing excessive evaporation (Blyth et al., 2019),

- Enhancing infiltration of precipitation into the soil column (Largeron et al., 2018),

- Addition of lateral and sub-surface flows in the land model (e.g., Batelis et al., 2020).

A number of these enhancements are being currently delivered and coordinated through the Hydro-JULES programme (https://hydrojules.org/). Hydro-JULES research is also deriving improved land surface parameters through a data assimilation framework using the COSMOS observations (Cooper et al., 2020; Pinnington et al., 2020).

However, it is notable that relative to the JULES implementation used in this paper, the developments of Martinez-de la Torre et al. (2019) were based on catchment-specific assessments, using a different model grid with different soil ancillary information, and with a different land surface initialisation approach. For land surface model focussed enhancements, such as to be delivered from Hydro-JULES, to be readily applied and demonstrated in the UK coupled system, care needs to be taken to align research configurations as far as possible. A key gap remains an imperative for greater flexibility and 
transparency of methods for generating any new supporting data sets and configuration parameters. At the same time, greater technical flexibility is required to limit the extent to which developments of one model component are constrained by technical details of any other. For example, the atmosphere and land surface components used in this study are currently defined on a common model grid to support implicit atmosphere-land coupling, and thereby the river routing in CPLriv has been applied only on the fixed $1.5 \mathrm{~km}$ resolution inner region of the domain whereas gridded hydrological model development for the UK tend to focus on $1 \mathrm{~km}$ resolution definitions (e.g., Robinson et al., 2019). Future work is planned to be able run river routing as a separate code executable to the rest of the land surface component in order to take advantage of the flexibility of model grids and interpolation of fields provided by coupling libraries, enabling simulation of river flows on a more hydrology rather than atmosphere relevant model grid. This might be viewed as a first step towards even further flexibility of geographical definitions and model grids across different sub-components of the land surface representation (e.g., Chaney et al., 2016).

\subsection{Towards more useful coupled system hydrological predictions}

The recent development of a UK regional soil moisture analysis for NWP by Gómez et al. (2020) provides opportunities to explore the impact of improved soil moisture updating on system performance. Several authors have highlighted the value of river flow assimilation for improving both river flow and soil moisture (e.g., McMillan et al., 2013; Sun et al., 2016; Tian et al., 2019; Warrach-Sagi \& Wulfmeyer, 2010). This will be of benefit in the UK context, but there are first order model biases that are worth addressing as a more immediate development priority. As advocated by Clark et al. (2015), there also remain opportunities to improve the river flow parameterization, for example by implementing a 1-D diffusive wave solution.

There is also a strong requirement to move to the assessment of land surface and river flow simulations in probabilistic terms. Work is in progress to run the UK coupled system in ensemble mode, with the atmosphere component driven by the MOGREPS-UK operational NWP ensemble (Porson et al., 2020). Driving regional river flow predictions with an ensemble of precipitation input, and introducing stochastic and parameter perturbations in the land surface and river routing components offers many opportunities to better understand the propagation of uncertainty through the system, as well as consider appropriate design of regional coupled ensemble systems when coupling a range of potential flow solutions with ensemble ocean model components.

\section{5 | Linking improved hydrological simulation to coastal ocean predictions}

The impact of modifying the river discharge from the land into the coastal ocean around the UK has been quantified for winter 2013/14 While differences between CPLriv and CPLclim ocean results demonstrate some sensitivity, this analysis also highlights that the exact details of the river flow simulation are of second order importance to other coastal ocean processes. It will be interesting to revisit this analysis when the CPLriv discharges are not biased low relative to observations, and to undertake more detailed analysis of the impacts for specific case studies of coastal flooding and tidal locking in a multi-hazard context. Assessing the sensitivity of the near-coastal ocean to river discharge is also hampered by the limited availability of in-situ salinity observations around the UK coast, with the L4 profile observations presented here being a very rare and valuable resource. A brief comparison between CPLriv salinity results with SMOS satellite derived salinity products (Olmedo et al., 2021) proved inconclusive due to limited data availability in the near-coastal regions where river discharges were impacting ocean simulations.

The UK coastal ocean response to the characteristics of freshwater inflow is found to be relatively small in this study, with broad scale features of CPLriv and CPLclim remaining similar despite different river discharge forcing. For other regions, the influence of ocean stratification induced by precipitation and freshwater inflow remains an area of active research. For example, Gévaudan et al. (2021) suggest that salinity stratification in the north-western tropical Atlantic induces a significant increase of SST (by 0.2-0.5 K) leading to a $19 \%$ increase in summer rainfall, and much weaker impacts in winter. Krishnamohan et al. (2019) reviewed the hypotheses that strong salinity stratification due to large freshwater inflow in the northern Bay of Bengal inhibits vertical mixing of heat and maintains warm sea surface temperatures and enhances rainfall. In their assessment based on coarser $25 \mathrm{~km}$ resolution simulations with climatological river inputs, they in fact found little sensitivity of SST or precipitation to large changes in Bay of Bengal salinity stratification. However, the role of the freshwater-influenced mixed layer on the evolution of tropical cyclones in the region is also recognized (e.g., Qiu et al., 2019; Yesubabu et al., 2021), and further studies assessing atmosphereland-ocean feedbacks at finer model resolutions that enable more explicit representation of atmospheric convection and ocean eddies would be welcome. These examples further motivate the need for accurate predictions of freshwater flows in global and regional scale coupled prediction systems when considering atmosphere-ocean feedbacks.

Beyond being able to sample a broader range of meteorological and land surface conditions, extending the simulation period towards multi-annual timescales will enable assessment of the sensitivity of UK coastal oceans to freshwater influence and accuracy of river flow predictions as a function of seasonal and tidal cycles for locations of interest.

\section{6 | Beyond physical processes towards regional earth system simulation}

Finally, it is worth revisiting the vision for more dynamical coupling of the water cycle in the context of Earth System processes at regional scales. These extend beyond physical couplings between components into provision of capabilities to deliver forecasts and assessments of 
environmental changes on biogeochemical processes, and ultimately to include the role of anthropogenic influence on these. The modelling framework presented here provides a good basis from which to advance coupling to marine and terrestrial biogeochemistry models and inform questions of water quality and marine health. This also emphasizes that the value of developing accurate predictions of hydrological processes in land surface models extends beyond an ability to provide predictions of river flow and water availability, but to being an integral part of whole system simulations of the Earth System across scales. This vision was well characterized again by Beven (2007), as follows:

Built on the fluxes within those models, air and water pollutant transport models and biogeochemical models could, additionally, be implemented locally within the regional scale domain. Each component should be able to assimilate data transmitted from field sites and to assess the uncertainty in the predictions. Such an integrated system should operate both in real time, assimilating data and boundary conditions from larger scale models and displaying the 'current state of the environment', as well as providing the potential to update model predictions into the future under different scenarios."

\section{5 | CONCLUSIONS}

A km-scale regional coupled simulation system has been presented with results showing broadly representative predictions of precipitation, soil moisture, river flow and coastal ocean state for free-running simulations focussed on the UK for winter 2013/14. Three specific questions were set out in Section 1.

(a) Are $\mathrm{km}$-scale regional simulations of precipitation and soil moisture sufficiently accurate to provide useful forcing for distributed modelling of river flows across UK catchments?

For winter 2013/14, a west-east bias in accumulated precipitation simulations has been identified, with rainfall too low over upland areas of western UK and too much rainfall advected further east. This assessment has been unable to determine how limiting these biases are for modelling of river flows across the UK-in practice there are too many processes within the coupled hydro-meteorological modelling chain. Some of the challenges and opportunities of using coupled systems as part of the assessment of hydrological model performance were discussed in Section 4. A further limiting constraint for the time of interest in this study is that there were relatively few in-situ observations of soil moisture state, although the direct comparison presented shows moderately good agreement between simulations and observations where available.

There are atmosphere and land surface model developments that can be implemented to further improve the simulated river flow results presented, through enhancements to their process representation. This study therefore provides a useful first indication of the hydrological performance of the UK $\mathrm{km}$-scale regional coupled system that will be revisited in future when assessing the impact of changes to model components on the whole system (e.g., Deacu et al., 2012).

(b) How sensitive are regional ocean simulations of the near-coastal region around the UK to the representation and accuracy of input river flows?

Dynamically coupled prediction systems enable new insight to be gained on the 'hydrological response' of the near-coastal ocean to hydro-meteorological processes. For winter 2013/14, the near coastal salinity can be modified by more than 2 psu in regions impacted by river discharge around the UK coast due to the change from a climatological to simulated river flow. On average, the impact on temperature is considerably smaller, and the sensitivity to river flows shown to be of second-order importance relative to other sources of near-coastal ocean errors.

It has not been possible to address the extent to which accuracy of simulated input river flows impacts near-coastal ocean predictions in this study. This question will be better addressed in future through returning to an assessment of the extent to which ocean predictions for winter 13/14 and other seasons can be improved when using updated model configurations in which the simulation of UK river flows is improved, for example by reducing spatial precipitation biases from the atmosphere model or adding groundwater parameterisation in the land surface model. The sensitivity demonstrated in this study between input climatological and simulated river flows suggests that broad scale sensitivity due to changes in the simulated flow will be relatively minor overall, but impacts may be better assessed focussing on specific locations and times of interest.

(c) What do these results imply for future component model development?

This study demonstrates the feasibility of a vision for more dynamically coupled systems to provide useful predictions at scales relevant to catchment and coastal processes, but also highlights the challenges of being able to develop improved predictions within systems with multiple sources of model uncertainties and where several variables of interest within the hydrological prediction chain are relatively poorly observed. Development priorities have been identified for further improving the quality of these predictions using the UMJULES-NEMO modelling framework. Key to this is a need to deliver improvements to model parameterizations and related data across components. This includes priorities to reduce precipitation biases, improving land surface model representation of evaporation and infiltration processes; addition of missing processes, notably of lateral and sub-surface water flows in the land surface model; and a move to more assimilative and probabilistic modelling frameworks.

Whilst the details of the model configuration, supporting datasets and validation protocols are specific to the modelling framework presented here their discussion draws out generalizable insights which are 
anticipated to of value to the wider community. The first insight relates to the value of assessing model performance over extended periods with free-running simulations. This is particularly important for assessment of precipitation characteristics (e.g., Figure 2), with understanding of model performance often based on validation activities focussed on operational numerical weather prediction and regional models that are better constrained by shorter simulations and frequently updating initialisation. This requirement is increasingly being addressed through closer alignment of convective-scale model development and evaluation in the context of their growing application across both weather and climate timescales (e.g., Giorgi, 2019).

A second insight is the need to use available in-situ soil moisture observations routinely as a core part of evaluating atmosphere-land coupled models (e.g., Figure 5). This is not currently common practice, with the resulting risk that the land surface hydrology becomes a "sink" for errors in atmospheric forcing and model uncertainties (e.g., Drusch \& Viterbo, 2007). Even given observation uncertainties and challenges in translating between observed and equivalent model variables, monitoring the relative spatial distributions and temporal variability of simulated soil moisture to in-situ networks such as COSMOS-UK and international comparators is shown to be of value for model development and needs to be championed across modelling groups. This argument can be extended to include utility of translating model outputs to river flow (e.g., Figure 8) to compare with a more widely observed quantity, ideally using an ensemble of river flow model configurations to indicate the degree of confidence to which input simulated runoffs are representative.

Third, through assessing a model chain with interacting components, this study highlights the value of using coupled models to understand interconnected environmental problems. The near-coastal ocean response to changing river discharge (e.g., Figure 10) gives a measure of its sensitivity to relatively modest alterations to the input forcing. From a model development perspective, demonstrating the sensitivity of ocean models to the input river discharge will provide more confidence in resulting operational predictions (e.g., Tonani et al., 2019). Moreover, this study demonstrates an experimental framework with which to assess how environmental changes in the atmosphere, terrestrial or marine water cycles might interact through other components of the Earth system. Assessment of such model frameworks would benefit from evaluation of simulations over longer periods, extending from months in this study to multi-annual studies. These will also provide a strong basis for further exploration to more biogeochemical aspects of the Earth System at regional scales in future.

\section{ACKNOWLEDGEMENTS}

The authors are grateful to many colleagues for their contributions to this work. Juan Castillo has led on the technical development of the UK regional coupled system, and Dan Copsey developed the 1-d river coupling approach implemented here. We acknowledge the open access to invaluable observations data, and in particular the HadUKGrid precipitation record curated by the National Climate Information Centre at the Met Office, COSMOS-UK soil moisture and National
River Flow Archive river flow observations curated by the UK Centre for Ecology \& Hydrology (UK-CEH), and L4 ocean salinity and temperature profiles provided by Plymouth Marine Laboratory, with specific thanks to Tim Smyth. Provision of G2G and DECIPHeR sources of river flow simulations from the MaRIUS project is acknowledged, with specific thanks to the UK-CEH Environmental Information Data Centre, Vicky Bell, and Gemma Coxon.

This research has been carried out under national capability funding as part of the UK Environmental Prediction collaboration between the Met Office, UK Centre for Ecology and Hydrology, National Oceanography Centre, and Plymouth Marine Laboratory.

We are very grateful to two anonymous reviewers for their constructive assessment of the first submitted paper and their valuable contributions to improving this paper.

\section{DATA AVAILABILITY}

Coupled model data used in this study amount to several Tb, archived to tape storage at the Met Office. These data can be readily shared with interested collaborators on contacting the lead author. Details on obtaining the model codes used to produce these results are set out in the Appendices of Lewis et al. (2019a).

Details and links to freely access the HadUK-Grid precipitation data are available from https://www.metoffice.gov.uk/research/ climate/maps-and-data/data/haduk-grid/datasets.

COSMOS-UK observation data are available from https://cosmos. ceh.ac.uk/. NRFA river flow observation data are available from https:// nrfa.ceh.ac.uk/. L4 ocean observations are accessible via https://www. westernchannelobservatory.org.uk/data.php. G2G model data are available from https://doi.org/10.5285/f52f012d-9f2e-42cc-b628-9cdea4fa $3 \mathrm{baO}$ and the DECIPHeR ensemble flow simulations from https://doi. org/10.5285/d770b12a-3824-4e40-8da1-930cf9470858.

\section{ORCID}

Huw W. Lewis (D) https://orcid.org/0000-0003-3581-6459

\section{REFERENCES}

Anderson, S. R., Csima, G., Moore, R. J., Mittermaier, M., \& Cole, S. J. (2019). Towards operational joint river flow and precipitation ensemble verification: Considerations and strategies given limited ensemble records. Journal of Hydrology, 577, 123966. https://doi.org/10.1016/j. jhydrol.2019.123966

Batelis, S.-C., Rahman, M., Kollet, S., Woods, R., \& Rosolem, R. (2020). Towards the representation of groundwater in the joint UKland environment simulator. Hydrological Processes, 34(13), 2843-2863.

Bell, V. A., Kay, A. L., Jones, R. G., \& Moore, R. J. (2007). Development of a high resolution grid-based river flow model for use with regional climate model output. Hydrology and Earth System Sciences, 11(1), 532549. https://doi.org/10.5194/hess-11-532-2007

Bell, V. A., Kay, A. L., Rudd, A. C., \& Davies, H. N. (2018). The MaRIUSG2G datasets: Grid-to-grid model estimates of flow and soil moisture for Great Britain using observed and climate model driving data. Geoscience Data Journal, 5(2), 63-72. https://doi.org/10.1002/gdj3.55

Best, M. J., Pryor, M., Clark, D. B., Rooney, G. G., Essery, R. L. H., Ménard, C. B., Edwards, J. M., Hendry, M. A., Porson, A., Gedney, N., Mercado, L. M., Sitch, S., Blyth, E., Boucher, O., Cox, P. M., Grimmond, C. S. B., \& Harding, R. J. (2011). The Joint UK Land Environment Simulator 
(JULES), model description - Part 1: Energy and water fluxes. Geoscientific Model Development, 4(3), 677-699. https://doi.org/10. 5194/gmd-4-677-2011

Beven, K. (2007). Towards integrated environmental models of everywhere: Uncertainty, data and modelling as a learning process. Hydrology and Earth System Sciences, 11, 460-467. https://doi.org/10.5194/ hess-11-460-2007

Blyth, E. M., Arora, V. K., Clark, D. B., Dadson, S. J., De Kauwe, M. G. Lawrence, D. M., Melton, J. R., Pongratz, J., Turton, R. H., Yoshimura, K., \& Yuan, H. (2021). Advances in Land Surface Modelling. Current Climate Change Reports, 7(2), 45-71. https://doi.org/10.1007/s40641021-00171-5

Blyth, E. M., Martinez-de la Torre, A., \& Robinson, E. L. (2019). Trends in evapotranspiration and its drivers in Great Britain: 1961 to 2015. Progress in Physical Geography, 43(5), 666-693. https://doi.org/10.1177/ 0309133319841891

Bush, M., Allen, T., Bain, C., Boutle, I., Edwards, J., Finnenkoetter, A., Franklin, C., Hanley, K., Lean, H., Lock, A., Manners, J., Mittermaier, M., Morcrette, C., North, R., Petch, J., Short, C., Vosper, S., Walters, D. Webster, S., ... Zerroukat, M. (2020). The first Met Office Unified Model-JULES Regional Atmosphere and Land configuration, RAL1. Geoscientific Model Development, 13(4), 1999-2029. https://doi.org/ 10.5194/gmd-13-1999-2020

Chan, S. C., Kahana, R., Kendon, E. J., \& Fowler, H. J. (2018). Projected changes in extreme precipitation over Scotland and northern England using a high-resolution regional climate model. Climate Dynamics, 51(9), 3559-3577. https://doi.org/10.1007/s00382-018-4096-4

Chaney, N. W., Metcalfe, P., \& Wood, E. F. (2016). HydroBlocks: A fieldscale resolving land surface model for application over continental extents. Hydrological Processes, 30(20), 3543-3559. https://doi.org/ 10.1002/hyp.10891

Ciurean, R., Gill, J., Reeves, H. J., O'Grady, S., \& Aldridge, T. (2018). Review of environmental multihazards research and risk assessments. British Geological Survey, Open Report, OR/18/057 (p. 86). British Geological Survey / Natural Environment Research Council. http://nora.nerc.ac. uk/id/eprint/524399

Clark, D. B., \& Gedney, N. (2008). Representing the effects of subgrid variability of soil moisture on runoff generation in a land surface model. Journal of Geophysical Research: Atmospheres, 113, D10111. https:// doi.org/10.1029/2007JD008940

Clark, M. P., Fan, Y., Lawrence, D. M., Adam, J. C., Bolster, D., Gochis, D. J., Hooper, R. P., Kumar, M., Leung, L. R., Mackay, D. S., Maxwell, R. M., Shen, C., Swenson, S. C., \& Zeng, X. (2015). Improving the representation of hydrologic processes in Earth System Models. Water Resources Research, 51(8), 5929-5956. https://doi.org/10.1002/2015WR017096

Cooper, E., Blyth, E., Cooper, H., Ellis, R., Pinnington, E., \& Dadson, S. J. (2020). Using data assimilation to optimize pedotransfer functions using large-scale in-situ soil moisture observations. Hydrology and Earth System Sciences Discussions, 2020, 1-20. https://doi.org/10. 5194/hess-2020-359

Cooper, H. M., Bennett, E., Blake, J., Blyth, E., Boorman, D., Cooper, E., Evans, J., Fry, M., Jenkins, A., Morrison, R., Rylett, D., Stanley, S., Szczykulska, M., Trill, E., Antoniou, V., Askquith-Ellis, A., Ball, L., Brooks, M., Clarke, M. A., ... Winterbourn, B. (2021). COSMOS-UK: national soil moisture and hydrometeorology data for environmental science research. Earth System Science Data, 13(4), 1737-1757. https://doi.org/10.5194/essd-13-1737-2021

Cosby, B. J., Hornberger, G. M., Clapp, R. B., \& Ginn, T. R. (1984). A statistical exploration of the relationships of soil moisture characteristics to the physical properties of soils. Water Resources Research, 20(6), 682690. https://doi.org/10.1029/WR020i006p00682

Couasnon, A., Eilander, D., Muis, S., Veldkamp, T. I. E., Haigh, I. D., Wahl, T., Winsemius, H. C., \& Ward, P. J. (2020). Measuring compound flood potential from river discharge and storm surge extremes at the global scale. Natural Hazards and Earth System Sciences, 20, 489-504. https://doi.org/10.5194/nhess-20-489-2020

Coxon, G., Freer, J., Lane, R., Dunne, T., Knoben, W. J. M., Howden, N. J. K., Quinn, N., Wagener, T., \& Woods, R. (2019a). DEClPHeR v1: Dynamic fluxEs and Connectlvity for predictions of HydRology. Geoscientific Model Development, 12, 2285-2306. https://doi.org/ 10.5194/gmd-12-2285-2019

Coxon, G., Freer, J., Lane, R., Dunne, T., Knoben, W. J. M., Howden, N. J. K., Quinn, N., Wagener, T., \& Woods, R. (2019b). DECIPHeR model estimates of daily flow for 1366 gauged catchments in Great Britain (1962-2015) using observed driving data. NERC Environmental Information Data Centre. https://doi.org/10.5285/d770b12a3824-4e40-8da1-930cf9470858

Craig, A., Valcke, S., \& Coquart, L. (2017). Development and performance of a new version of the OASIS coupler, OASIS3-MCT_3.0. Geoscientific Model Development, 10, 3297-3308. https://doi.org/10.5194/gmd10-3297-2017

Dadson, S. J., Bell, V. A., \& Jones, R. G. (2011). Evaluation of a grid-based river flow model configured for use in a regional climate model. Journal of Hydrology, 411(3), 238-250. https://doi.org/10.1016/j.jhydrol. 2011.10.002

Deacu, D., Fortin, V., Klyszejko, E., Spence, C., \& Blanken, P. D. (2012). Predicting the Net Basin supply to the Great Lakes with a Hydrometeorological model. Journal of Hydrometeorology, 13(6), 1739-1759. https://doi.org/10.1175/JHM-D-11-0151.1

Drusch, M., \& Viterbo, P. (2007). Assimilation of screen-level variables in ECMWF's integrated forecast system: A study on the impact on the forecast quality and analyzed soil moisture. Monthly Weather Review, 135(2), 300-314. https://doi.org/10.1175/MWR3309.1

Durnford, D., Fortin, V., Smith, G. C., Archambault, B., Deacu, D., Dupont, F., Dyck, S., Martinez, Y., Klyszejko, E., MacKay, M., Liu, L., Pellerin, P., Pietroniro, A., Roy, F., Vu, V., Winter, B., Yu, W., Spence, C., Bruxer, J., \& Dickhout, J. (2018). Toward an Operational Water Cycle Prediction System for the Great Lakes and St. Lawrence River. Bulletin of the American Meteorological Society, 99(3), 521-546. https://doi.org/10. 1175/BAMS-D-16-0155.1

Evans, J. G., Ward, H. C., Blake, J. R., Hewitt, E. J., Morrison, R., Fry, M., Ball, L. A., Doughty, L. C., Libre, J. W., Hitt, O. E., Rylett, D., Ellis, R. J., Warwick, A. C., Brooks, M., Parkes, M. A., Wright, G. M. H., Singer, A. C., Boorman, D. B., \& Jenkins, A. (2016). Soil water content in southern England derived from a cosmic-ray soil moisture observing system COSMOS-UK. Hydrological Processes, 30, 4987-4999. https://doi.org/ 10.1002/hyp.10929

Fersch, B., Senatore, A., Adler, B., Arnault, J., Mauder, M., Schneider, K., Völksch, I., \& Kunstmann, H. (2020). High-resolution fully coupled atmospheric-hydrological modeling: a cross-compartment regional water and energy cycle evaluation. Hydrology and Earth System Sciences, 24, 2457-2481. https://doi.org/10.5194/hess-24-2457-2020

Fersch, B., Senatore, A., Adler, B., Arnault, J., Mauder, M., Schneider, K., ... Kunstmann, H. (2019). High-resolution fully-coupled atmospherichydrological modeling: A cross-compartment regional water and energy cycle evaluation. Hydrology and Earth System Sciences Discussions, 2019, 1-37. https://doi.org/10.5194/hess-2019-478

Flack, D. L. A., Skinner, C. J., Hawkness-Smith, L., O'Donnell, G., Thompson, R. J., Waller, J. A., Chen, A. S., Moloney, J., Largeron, C., Xia, X., Blenkinsop, S., Champion, A. J., Perks, M. T., Quinn, N., \& Speight, L. J. (2019). Recommendations for improving integration in National end-to-end Flood Forecasting Systems: An overview of the FFIR (flooding from intense rainfall) Programme. Water, 2019(11), 725. https://doi.org/10.3390/w11040725

Gévaudan, M., Jouanno, J., Durand, F., Morvan, G., Renault, L., \& Samson, G. (2021). Influence of ocean salinity stratification on the tropical Atlantic Ocean surface. Climate Dynamics, 57(1), 321-340. https://doi.org/10.1007/s00382-021-05713-z 
Giorgi, F. (2019). Thirty years of regional climate modeling: Where are we and where are we going next? Journal of Geophysical Research: Atmospheres, 124(11), 5696-5723. https://doi.org/10.1029/2018JD030094

Gómez, B., Charlton-Pérez, C. L., Lewis, H., \& Candy, B. (2020). The Met Office operational soil moisture analysis system. Remote Sensing, 12(22), 3691. https://doi.org/10.3390/rs12223691

Graham, J. A., O'Dea, E., Holt, J., Polton, J., Hewitt, H. T., Furner, R., Guihou, K., Brereton, A., Arnold, A., Wakelin, S., Castillo Sanchez, J. M., \& Mayorga Adame, C. G. (2018). AMM15: a new high-resolution NEMO configuration for operational simulation of the European north-west shelf. Geoscientific Model Development, 11, 681-696. https://doi.org/10.5194/gmd-11-681-2018

Harrigan, S., Hannaford, J., Muchan, K., \& Marsh, T. J. (2018). Designation and trend analysis of the updated UK Benchmark Network of river flow stations: the UKBN2 dataset. Hydrology Research, 49(2), 552567. https://doi.org/10.2166/nh.2017.058

Huntingford, C., Marsh, T., Scaife, A. A., Kendon, E. J., Hannaford, J., Kay, A. L., Lockwood, M., Prudhomme, C., Reynard, N. S., Parry, S., Lowe, J. A., Screen, J. A., Ward, H. C., Roberts, M., Stott, P. A., Bell, V. A., Bailey, M., Jenkins, A., Legg, T., ... Allen, M. R. (2014). Potential influences on the United Kingdom's floods of winter 2013/14. Nature Climate Change, 4(9), 769-777. https://doi.org/10.1038/nclimate2314

Kendon, M., \& McCarthy, M. (2015). The UK's wet and stormy winter of 2013/2014. Weather, 70(2), 40-47. https://doi.org/10.1002/wea. 2465

Krishnamohan, K. S., Vialard, J., Lengaigne, M., Masson, S., Samson, G., Pous, S., Neetu, S., Durand, F., Shenoi, S. S. C., \& Madec, G. (2019). Is there an effect of Bay of Bengal salinity on the northern Indian Ocean climatological rainfall? Topical Studies in Oceanography. https:// doi.org/10.1016/j.dsr2.2019.04.003

Krishnamohan, K. S., Vialard, J., Lengaigne, M., Masson, S., Samson, G., Pous, S., ... Madec, G. (2019). Is there an effect of bay of Bengal salinity on the northern Indian Ocean climatological rainfall? Deep Sea Research Part II: Topical Studies in Oceanography, 166, 19-33. https:// doi.org/10.1016/j.dsr2.2019.04.003

Largeron, C., Cloke, H. L., Verhoef, A., Martinez-de-la-Torre, A., \& MuellerQuintino, A. (2018). Impact of the representation of the infiltration on the river flow during intense rainfall events in Jules. ECMWF technical. Memorandum, 821. 1-42. https://doi.org/10.21957/nkky9s1hs

Lewis, H., Mittermaier, M., Mylne, K., Norman, K., Scaife, A., Neal, R., Pierce, C., Harrison, D., Jewell, S., Kendon, M., Saunders, R., Brunet, G., Golding, B., Kitchen, M., Davies, P., \& Pilling, C. (2015). From months to minutes-exploring the value of high-resolution rainfall observation and prediction during the UK winter storms of 2013/2014. Royal Meteorological Society, 22, 90-104. https://doi.org/10.1002/met.1493

Lewis, H. W., Castillo Sanchez, J. M., Arnold, A., Fallmann, J., Saulter, A., Graham, J., Bush, M., Siddorn, J., Palmer, T., Lock, A., Edwards, J., Bricheno, L., Martínez-de la Torre, A., \& Clark, J. (2019). The UKC3 regional coupled environmental prediction system. Geoscientific Model Development, 12, 2357-2400. https://doi.org/10.5194/gmd-12-23572019

Lewis, H. W., Castillo Sanchez, J. M., Graham, J., Saulter, A., Bornemann, J., Arnold, A., Fallmann, J., Harris, C., Pearson, D., Ramsdale, S., Martínezde la Torre, A., Bricheno, L., Blyth, E., Bell, V. A., Davies, H., Marthews, T. R., O'Neill, C., Rumbold, H., O'Dea, E., ... Siddorn, J. (2018). The UKC2 regional coupled environmental prediction system. Geoscientific Model Development, 11, 1-42. https://doi.org/10.5194/gmd-11-12018

Lewis, H. W., Siddorn, J., Castillo Sanchez, J. M., Petch, J., Edwards, J. M., \& Smyth, T. (2019). Evaluating the impact of atmospheric forcing and air-sea coupling on near-coastal regional ocean prediction. Ocean Science, 15(3), 761-778. https://doi.org/10.5194/ os-15-761-2019

Madec, G., \& NEMO System Team. (2020). NEMO Ocean engine. Scientific notes of climate Modelling center (27) - ISSN 1288-1619. Institut PierreSimon Laplace (IPSL). https://doi.org/10.5281/zenodo.1464816
Marsh, T., Sanderson, F., \& Swain, O. (2015). Derivation of the UK national and regional runoff series. Wallingford, NERC/Centre for Ecology \& Hydrology, 10. http://nora.nerc.ac.uk/id/eprint/510580/

Martinez-de la Torre, A., Blyth, E. M., \& Weedon, G. P. (2019). Using observed river flow data to improve the hydrological functioning of the JULES land surface model (vn4.3) used for regional coupled modelling in Great Britain (UKC2). Geoscientific Model Development, 12(2), 765-784. https://doi.org/10.5194/gmd-12-765-2019

McMillan, H. K., Hreinsson, E. Ö., Clark, M. P., Singh, S. K., Zammit, C., \& Uddstrom, M. J. (2013). Operational hydrological data assimilation with the recursive ensemble Kalman filter. Hydrology and Earth System Sciences, 17(1), 21-38. https://doi.org/10.5194/hess-17-212013

Ming, X., Liang, Q., Xia, X., Li, D., \& Fowler, H. J. (2020). Real-time flood forecasting based on a high-performance $2 \mathrm{D}$ hydrodynamic model and numerical weather predictions. Water Resources Research, 56(7), e2019WR025583. https://doi.org/10.1029/2019WR025583

Moore, R. J. (2007). The PDM rainfall-runoff model. Hydrology and Earth System Sciences, 11(1), 483-499. https://doi.org/10.5194/hess-11483-2007

Muchan, K., Lewis, M., Hannaford, J., \& Parry, S. (2015). The winter storms of $2013 / 2014$ in the UK: Hydrological responses and impacts. Weather, 70(2), 55-61. https://doi.org/10.1002/wea.2469

Mueller-Quintino, A., Dutra, E., Cloke, H. L., Verhoef, A., Balsamo, G., \& Pappenberger, F. (2016). Water infiltration and redistribution in land surface models. ECMWF Technical Memoranda, 791, 1-23. https://doi. org/10.21957/ppksejqu9

Neumann, J., Arnal, L., Magnusson, L., \& Cloke, H. (2015). The 2013/14 Thames Basin floods: Do improved meteorological forecasts Lead to more skillful hydrological forecasts at seasonal time scales? Journal of Hydrometeorology, 19(6), 1059-1075. https://doi.org/10.1175/JHMD-17-0182.1

Olmedo, E., González-Haro, C., Hoareau, N., Umbert, M., GonzálezGambau, V., Martinez, J., \& Turiel, A. (2021). Nine years of SMOS Sea surface salinity global maps at the Barcelona expert center. Earth System Science Data Discussions, 2020, 1-49. https://doi.org/10.5194/ essd-2020-232

Olmedo, E., González-Haro, C., Hoareau, N., Umbert, M., GonzálezGambau, V., Martinez, J., Gabarro, C., \& Turiel, A. (2021). Nine years of SMOS sea surface salinity global maps at the Barcelona Expert Center. Earth System Science Data, 13(2), 857-888. https://doi.org/10.5194/ essd-13-857-2021

Perry, M., \& Hollis, D. (2005). The generation of monthly gridded datasets for a range of climatic variables over the UK. International Journal of Climatology, 25(8), 1041-1054. https://doi.org/10.1002/joc.1161

Pilling, C., Dodds, V., Cranston, M., Price, D., Harrison, T., \& How, A. (2016). Chapter 9- flood forecasting - A National Overview for Great Britain. In T. E. Adams \& T. C. Pagano (Eds.), Flood forecasting (pp. 201-247). Academic Press. https://doi.org/10.1016/B978-0-12801884-2.00009-8

Pinnington, E., Amezcua, J., Cooper, E., Dadson, S., Ellis, R., Peng, J., \& Quaife, T. (2020). Improving soil moisture prediction of a highresolution land surface model by Parameterising Pedotransfer functions through assimilation of SMAP satellite data. Hydrology and Earth System Sciences Discussions, 2020, 1-24. https://doi.org/10.5194/ hess-2020-303

Pinnington, E., Amezcua, J., Cooper, E., Dadson, S., Ellis, R., Peng, J., Robinson, E., Morrison, R., Osborne, S., \& Quaife, T. (2021). Improving soil moisture prediction of a high-resolution land surface model by parameterising pedotransfer functions through assimilation of SMAP satellite data. Hydrology and Earth System Sciences, 25(3), 1617-1641. https://doi.org/10.5194/hess-25-1617-2021

Porson, A. N., Carr, J. M., Hagelin, S., Darvell, R., North, R., Walters, D., Mylne, K. R., Mittermaier, M. P., Willington, S., \& Macpherson, B. (2020). Recent upgrades to the Met Office convective-scale ensemble: An hourly time-lagged 5-day ensemble. Quarterly Journal of the Royal 
Meteorological Society, 146(732), 3245-3265. https://doi.org/10. 1002/qj.3844

Qiu, Y., Han, W., Lin, X., West, B. J., Li, Y., Xing, W., Zhang, X., Arulananthan, K., \& Guo, X. (2019). Upper-Ocean response to the super tropical cyclone Phailin (2013) over the freshwater region of the bay of Bengal. Journal of Physical Oceanography, 49(5), 1201-1228. Retrieved Jul 16, 2021, from. https://journals.ametsoc.org/view/ journals/phoc/49/5/jpo-d-18-0228.1.xml

Rainaud, R., Brossier, C. L., Ducrocq, V., \& Giordani, H. (2017). Highresolution air-sea coupling impact on two heavy precipitation events in the Western Mediterranean. Quarterly Journal of the Royal Meteorological Society, 143(707), 2448-2462. https://doi.org/10.1002/qj. 3098

Roberts, N. M., Cole, S. J., Forbes, R. M., Moore, R. J., \& Boswell, D. (2009). Use of high-resolution NWP rainfall and river flow forecasts for advance warning of the Carlisle flood, north-West England. Meteorological Applications, 16(1), 23-34. https://doi.org/10.1002/ met.94

Robinson, E. L., Blyth, E. M., Clark, D. B., Finch, J., \& Rudd, A. C. (2017). Trends in atmospheric evaporative demand in Great Britain using high-resolution meteorological data. Hydrology and Earth System Sciences, 21, 1189-1224. https://doi.org/10.5194/hess-21-1189-2017

Rudd, A. C., Bell, V. A., \& Kay, A. L. (2017). National-scale analysis of simulated hydrological droughts (1891-2015). Journal of Hydrology, 550, 368-385. https://doi.org/10.1016/j.jhydrol.2017.05.018

Sellar, A. A., Jones, C. G., Mulcahy, J. P., Tang, Y., Yool, A., Wiltshire, A., O'Connor, F. M., Stringer, M., Hill, R., Palmieri, J., Woodward, S., de Mora, L., Kuhlbrodt, T., Rumbold, S. T., Kelley, D. I., Ellis, R., Johnson, C. E., Walton, J., Abraham, N. L., ... Zerroukat, M. (2019). UKESM1: Description and Evaluation of the U.K. Earth System Model. Journal of Advances in Modeling Earth Systems, 11(12), 4513-4558. https://doi. org/10.1029/2019MS001739

Senatore, A., Furnari, L., \& Mendicino, G. (2020). Impact of high-resolution sea surface temperature representation on the forecast of small Mediterranean catchments' hydrological responses to heavy precipitation. Hydrology and Earth System Sciences, 24(1), 269-291. https://doi.org/ 10.5194/hess-24-269-2020

Senatore, A., Mendicino, G., Gochis, D. J., Yu, W., Yates, D. N., \& Kunstmann, H. (2015). Fully coupled atmosphere-hydrology simulations for the Central Mediterranean: Impact of enhanced hydrological parameterization for short and long time scales. Journal of Advances in Modeling Earth Systems, 7(4), 1693-1715. https://doi.org/10.1002/ 2015 MS000510

Sibley, A., Cox, D., \& Titley, H. (2015). Coastal flooding in England and Wales from Atlantic and North Sea storms during the 2013/2014 winter. Weather, 70(2), 62-70. https://doi.org/10.1002/wea.2471

Smith, S. A., Vosper, S. B., \& Field, P. R. (2015). Sensitivity of orographic precipitation enhancement to horizontal resolution in the operational met Office weather forecasts. Meteorological Applications, 22(1), 1424. https://doi.org/10.1002/met.1352

Smyth, T. J., Fishwick, J. R., AL-Moosawi, L., Cummings, D. G., Harris, C., Kitidis, V., Rees, A., Martinez-Vicente, V., \& Woodward, E. M. S. (2009). A broad spatio-temporal view of the Western English Channel observatory. Journal of Plankton Research, 32, 585-601. https://doi. org/10.1093/plankt/fbp128

Stanley, S., Antoniou, V., Askquith-Ellis, A., Ball, L. A., Bennett, E. S., Blake, J. R., Boorman, D. B., Brooks, M., Clarke, M., Cooper, H. M., Cowan, N., Cumming, A., Evans, J. G., Farrand, P., Fry, M., Hitt, O. E., Lord, W. D., Morrison, R., Nash, G. V., ... Winterbourn, B. (2020). Daily and subdaily hydrometeorological and soil data (2013-2018) [COSMOS-UK]. NERC Environmental Information Data Centre. https://doi.org/10.5285/ 37702a54-b7a4-40ff-b62e-d14b161b69ca

Strajnar, B., Cedilnik, J., Fettich, A., Ličer, M., Pristov, N., Smerkol, P., \& Jerman, J. (2019). Impact of two-way coupling and sea-surface temperature on precipitation forecasts in regional atmosphere and ocean models. Quarterly Journal of the Royal Meteorological Society, 145(718), 228-242. https://doi.org/10.1002/qj.3425

Sun, L., Seidou, O., Nistor, I., \& Liu, K. (2016). Review of the Kalmantype hydrological data assimilation. Hydrological Sciences Journal, 61(13), 2348-2366. https://doi.org/10.1080/02626667.2015. 1127376

Thompson, B., Sanchez, C., Sun, X., Song, G., Liu, J., Huang, X.-Y., \& Tkalich, P. (2019). A high-resolution atmosphere-ocean coupled model for the western maritime continent: Development and preliminary assessment. Climate Dynamics, 52(7), 3951-3981. https://doi.org/10. 1007/s00382-018-4367-0

Tian, J., Liu, J., Yan, D., Ding, L., \& Li, C. (2019). Ensemble flood forecasting based on a coupled atmospheric-hydrological modeling system with data assimilation. Atmospheric Research, 224, 127-137. https://doi. org/10.1016/j.atmosres.2019.03.029

Tonani, M., Sykes, P., King, R. R., McConnell, N., Péquignet, A.-C., O'Dea, E., Graham, J. A., Polton, J., \& Siddorn, J. (2019). The impact of a new high-resolution ocean model on the Met Office North-West European Shelf forecasting system. Ocean Science, 15, 1133-1158. https://doi. org/10.5194/os-15-1133-2019

Varlas, G., Katsafados, P., Papadopoulos, A., \& Korres, G. (2018). Implementation of a two-way coupled atmosphere-ocean wave modeling system for assessing air-sea interaction over the Mediterranean Sea. Atmospheric Research, 208, 201-217. https://doi.org/10.1016/j. atmosres.2017.08.019

Wadey, M. P., Haigh, I. D., Nicholls, R. J., Brown, J. M., Horsburgh, K., Carroll, B., Gallop, S. L., Mason, T., \& Bradshaw, E. (2015). A comparison of the 31 January-1 February 1953 and 5-6 December 2013 coastal flood events around the UK. Frontiers in Marine Science, 2, 84. https://doi.org/10.3389/fmars.2015.00084

Wagener, T., Dadson, S. J., Hannah, D. M., Coxon, G., Beven, K., Bloomfield, J. P., Buytaert, W., Cloke, H., Bates, P., Holden, J., Parry, L., Lamb, R., Chappell, N. A., Fry, M., \& Old, G. (2021). Knowledge gaps in our perceptual model of Great Britain's hydrology. Hydrological Processes, 35(7), e14288. https://doi.org/10.1002/hyp.14288

Ward, N. D., Megonigal, J. P., Bond-Lamberty, B., Bailey, V. L., Butman, D., Canuel, E. A., Diefenderfer, H., Ganju, N. K., Goni, M. A., Graham, E. B., Hopkinson, C. S., Khangaonkar, T., Langley, J. A., McDowell, N. G., Myers-Pigg, A. N., Neumann, R. B., Osburn, C. L., Price, R. M., Rowland, J., ... Windham-Myers, L. (2020). Representing the function and sensitivity of coastal interfaces in Earth system models. Nature Communications, 11(1), 2458. https://doi.org/10.1038/s41467-02016236-2

Warner, J. C., Armstrong, B., He, R., \& Zambon, J. B. (2010). Development of a coupled ocean-atmosphere-wave-sediment transport (COAWST) modeling system. Ocean Modelling, 35(3), 230-244. https://doi.org/10. 1016/j.ocemod.2010.07.010

Warrach-Sagi, K., \& Wulfmeyer, V. (2010). Streamflow data assimilation for soil moisture analysis. Geoscientific Model Development, 3, 1-12. https://doi.org/10.5194/gmd-3-1-2010

Weedon, G. P., Prudhomme, C., Crooks, S., Ellis, R. J., Folwell, S. S., \& Best, M. J. (2015). Evaluating the performance of hydrological models via cross-spectral analysis: Case study of the Thames Basin, United Kingdom. Journal of Hydrometeorology, 16(1), 214-231. https://doi.org/10.1175/JHM-D-14-0021.1

Yang, Y., Turner, R., Carey-Smith, T., \& Uddstrom, M. (2020). A comparison of three model output statistics approaches for the bias correction of simulated soil moisture. Meteorological Applications, 27(6), e1970. https://doi.org/10.1002/met.1970

Yang, Y., Uddstrom, M., Revell, M., \& Moore, S. (2014). Soil moisture simulation by JULES in New Zealand: Verification and sensitivity tests. Meteorological Applications, 21(4), 888-897. https://doi.org/10.1002/ met.1426

Yesubabu, V., Kattamanchi, V. K., Vissa, N. K., Dasari, H. P., \& Sarangam, V. B. R. (2021). Impact of ocean mixed-layer depth 
initialization on the simulation of tropical cyclones over the bay of Bengal using the WRF-ARW model. Meteorological Applications, 27, e1862. https://doi.org/10.1002/met.1862

Zhang, Z., Wang, Y., Zhang, W., \& Xu, J. (2021). Coastal Ocean response and its feedback to typhoon Hato (2017) over the South China Sea: A numerical study. Journal of Geophysical Research: Atmospheres, 124, 13731-13749. https://doi.org/10.1029/2019JD031377
How to cite this article: Lewis, H. W., \& Dadson, S. J. (2021). A regional coupled approach to water cycle prediction during winter 2013/14 in the United Kingdom. Hydrological Processes, 35(12), e14438. https://doi.org/10.1002/hyp.14438 